This is a self-archived version of an original article. This version may differ from the original in pagination and typographic details.

Author(s): Pörhölä, Maili; Karhunen, Sanna; Rainivaara, Sini

Title: Bullying at school and in the workplace. A challenge for communication research.

Year: 2006

Version: Accepted version (Final draft)

Copyright: (c) Lawrence Erlbaum Associates, Inc., 2006.

Rights: In Copyright

Rights url: http://rightsstatements.org/page//nC/1.0/?language=en

Please cite the original version:

Pörhölä, M., Karhunen, S., \& Rainivaara, S. (2006). Bullying at school and in the workplace. A challenge for communication research.. In C. S. Beck (Ed.), Communication Yearbook (pp. 249301). Mahwah, NJ. Communication Yearbook, 30. 


\title{
Bullying at School and in the Workplace A Challenge for Communication Research
}

\author{
Table of Contents
}

- Defining Bullying at School and in the Workplace

Concepts Most Closely Related to Each Other Bullying

Mobbing

Harassment and sexual harassment

Characteristics of Bullying at School and in the Workplace 10

The nature of hurtful behavior $\quad 10$

The frequency and duration of hurtful behavior $\quad 12$

The imbalance of power between the parties 13

Intentionality and interpretability of hurtful behavior $\quad 15$

- The Prevalence of Bullying at School and in the Workplace 17

- Processes of Bullying as the Exchange and Appraisal of Messages 22

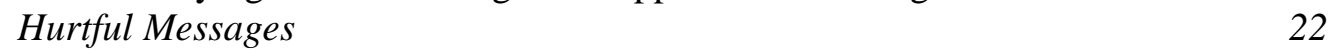

- Antecedents of Bullying at School and in the Workplace 33

Individual Differences in Communication Behavior 34

Bullying and Harassment as Group Processes 39

Organizational and Cultural Level Antecedents of Bullying and Harassment 45

- Managing the Costs of Bullying with Social Support 50

- Conclusion $\quad 53$

- References $\quad 57$ 


\title{
BULLYING AT SCHOOL AND IN THE WORKPLACE
}

A Challenge for Communication Research

\author{
Maili Pörhölä \\ University of Jyväskylä, Finland \\ Sanna Karhunen \\ University of Jyväskylä, Finland \\ Sini Rainivaara \\ University of Jyväskylä, Finland
}

The authors: Maili Pörhölä, Ph.D., is a Docent and a senior researcher of the Academy of Finland (University of Jyväskylä, Department of Communication, P.O.Box 35, FI-40014, University of

Jyväskylä; e-mail: porhola@jyu.fi). Sanna Karhunen and Sini Rainivaara are doctoral candidates at the University of Jyväskylä, Dept. of Communication.

\section{Acknowledgements}

This chapter was prepared within the research project no. 107301, "Mental violence in communication relationships at school and in the workplace", funded by the Academy of Finland. The authors wish to thank Dr. Christina Beck, the editor of Communication Yearbook 30, and the three anonymous reviewers for their most valuable comments and suggestions to the manuscript. Correspondence concerning this chapter should be addressed to Maili Pörhölä, Department of Communication, University of Jyväskylä, FI-40014, University of Jyväskylä, Finland; e-mail: maili.porhola@jyu.fi. 


\begin{abstract}
In this chapter, previous literature concerning school bullying and workplace harassment will be reviewed from a communication perspective. The chapter details the seriousness and extensiveness of bullying, both among children at school and adults at work. We aim to provoke discussion of how communication research and theory might help us in understanding and explaining bullying. As will be elaborated, bullying appears in interaction situations, mostly in the forms of verbal and nonverbal communication, it exists in the interpersonal relationship of bully and victim, and it can be associated with group communication processes and the structuration of groups, as well as with organizational and cultural communication processes. The benefits of applying communication theories and constructs to research focusing on bullying will be demonstrated, and suggestions for future studies will be made.
\end{abstract}




\section{Bullying at school and in the workplace: A challenge for communication research}

Bullying, mobbing, and harassment are examples of the terms used to describe negative, aggressive, and unjust behavior directed either at peers in school or at workmates, subordinates, or superiors in the workplace. The purpose of these intentionally aggressive or hurtful forms of behavior is to harm, subjugate, or humiliate the victim. Scholars regard bullying as a systematic and long-lasting subjection process, in which the participants are not equally matched. (e.g., Einarsen, 2000; Hazler \& Miller, 2001; Leymann, 1986; Naylor \& Cowie, 1999; Olweus, 1978, 1993;

Salmivalli, 1998; Vartia-Väänänen, 2003.)

Although, as we will demonstrate in the following section, some differences exist between the terms used to refer to this kind of behavior, we employ the term bullying in this chapter as an umbrella term covering both physical, verbal, and nonverbal attacks directed toward the victim or victims, as well as the direct and indirect forms of hurting, abusing, or socially excluding a peer or peers, superior or subordinates. In order to avoid annoying repetition, however, we also use the term harassment synonymously with bullying to refer to these phenomena.

In this chapter, our first goal is to detail the seriousness and extensiveness of bullying, both among children at school and adults at work. We examine bullying in the two contexts of school and workplace side by side in order to demonstrate the similarities and differences in behavior of children and adults in various bullying processes.

The second goal of this chapter is to demonstrate the ways in which bullying is realized in the processes of interaction between the parties and to show that it relates closely to various communication processes taking place between individuals and within groups. We claim that bullying is a communication phenomenon which can and should be examined by means of communication constructs and theories. As we elaborate in this chapter, bullying appears in 
interaction situations, mostly in the forms of verbal and nonverbal communication. It exists in the interpersonal relationship of bully and victim, and it can be associated with group communication processes and the structuration of groups. As our third goal, we aim to provoke discussion of how communication research and theory might help us in understanding and explaining bullying.

The literature reviewed in this chapter represents research conducted within several disciplines, including psychology, communication, and management. This research has been reported in disciplinary-specific as well as in multidisciplinary books and journals. Although we did not set out to offer cross-cultural comparisons, the literature reviewed has been conducted in various countries and in a variety of cultures, such as in Europe (especially in the Nordic countries), United States, Canada, Australia, and Asia, and, for this reason, it should provide a broad perspective on issues related to bullying. Perhaps most importantly, it illustrates the universality of bullying, both at school and in the workplace.

Since the research into workplace bullying and bullying at school originated in and has been strongly promoted in Scandinavia, the greater part of the literature examined in this chapter represents the research carried out by Scandinavian researchers. Notably, due to space constraints, this chapter cannot overview all of the extensive research on bullying at school and in the workplace, but rather, we quite selectively introduce some of the more important issues and problems to the understanding of which communication research may be able to make a significant contribution in the future.

In the following sections, previous literature concerning school bullying and workplace harassment will be reviewed from a communication perspective by raising issues central to communication research, such as the exchange and appraisal of messages, the establishment and maintenance of interpersonal relationships, the processes of group formation, organizational communication processes, and the effects of communication. The benefits of applying communication theories to research focusing on bullying will be demonstrated by examining some 
well-known communication theories and concepts as examples of the communicative understanding available. Throughout the chapter, suggestions for future studies will be made, investigations which involve treating bullying as a communication phenomenon.

\section{Defining Bullying at School and in the Workplace}

We begin with an examination of the concepts used in previous literature to describe bullying at school and in the workplace. A large number of terms have been used to label this phenomenon. A closer review of these terms indicates that some terms resemble each other very closely; they can be (and have been) used synonymously. In the following, we offer a short review of these terms.

Einarsen, Hoel, Zapf, and Cooper (2003) investigated bullying at work in Europe; Einarsen (2000) researched the concept in Scandinavian countries, and Keashly and Jagatic (2003) analyzed the corresponding American perspective. The concept of school bullying has also been considered broadly in previous literature (see, for example, Smith et al., 1999). Since extensive analyses of this kind are available, we do not seek to repeat those summaries in this chapter. Instead, we will briefly identify the most dominant similarities of (and differences between) the terms broadly used in the literature concerning bullying at school and in the workplace.

Therefore, we focus on three kinds of issues. First, we describe common features shared by several broadly-used definitions describing bullying both at school and in the workplace. Second, we highlight fundamental differences between the concepts of bullying at school and in the workplace, and third, we underscore the role of communication in prior definitions of bullying.

\section{Concepts Most Closely Related to Each Other}

While the terms bullying and victimization have become general in studies focusing on aggressive and abusive behavior demonstrated by children and adolescents at school (Olweus, 
2003), a great number of different labels have been applied to the corresponding behavior of adults at the workplace. These terms include harassment (Brodsky, 1976), scapegoating (Thylefors, 1987), mobbing (Leymann, 1990, 1996; Zapf, 1999), psychological terror (Leymann, 1996), work harassment (Björkqvist, Österman, \& Hjelt-Bäck, 1994), bullying (Adams, 1992; Einarsen \& Skogstad, 1996; Hoel \& Cooper, 2001; Salin, 2001), workplace aggression (Baron \& Neuman, 1996), abusive behavior and emotional abuse (Keashly, 1998; Keashly, Trott, \& MacLean, 1994). Terms such as petty tyranny (Ashforth, 1994) and workplace trauma (C.B. Wilson, 1991) have most clearly referenced the hostile behaviors of employers and supervisors directed at their subordinates. Additional terms for this kind of mental violence at work include employee mistreatment (Meares, Oetzel, Torres, Derkacs, \& Ginossar, 2004), employee abuse (C.B. Wilson, 1991), and employee emotional abuse (Lutgen-Sandvik, 2003). (For reviews, see Einarsen, 2000; Vartia-Väänänen, 2003.) Sexual harassment (Fitzgerald \& Shullman, 1993) can also constitute one form of bullying occurring at the workplace.

\section{Bullying.}

According to Olweus (2003), "[a] student is being bullied or victimised when he or she is exposed, repeatedly and over time, to negative actions on the part of one or more other students" (p. 62). Very similarly, Smorti, Menesini, and Smith (2003) described bullying as "a subcategory of aggressive behavior, but of a particularly vicious kind, inasmuch as it is directed, often repeatedly, toward a particular victim who is unable to effectively defend himself or herself" (p. 417). Olweus added that bullying behavior often occurs without apparent provocation, and it can be considered a form of abuse. He has also used the term peer abuse as a label for this phenomenon. According to Olweus, the abusive context and the relationship characteristics of the interacting partners set bullying apart from other forms of abuse, such as child abuse and spouse abuse.

Including the same elements as featured in the definitions given by Olweus (2003), as well as by Smorti and colleagues (2003), Batsche and Knoff (1994) defined bullying as "a form of 
aggression in which one or more students physically and/or psychologically (and more recently, sexually) harass another student repeatedly over a period of time" (p. 165), and Hoover, Oliver, and Hazler (1992) described it as "attempts by stronger students to harm a weaker victim, presumably in the absence of provocation. The attempted harm can be of either a physical or psychological nature and is longitudinal in nature” (p. 5). In the Peer Relations Questionnaire of Rigby and Slee, bullying is characterized as when "someone is deliberately hurting or frightening someone weaker than themselves for no good reason. This may be done in different ways: by hurtful teasing, threatening actions or gestures, name-calling or hitting or kicking" (as cited in Peterson \& Ribgy, 1999, p. 482).

Although bullying has widely been adopted in scientific literature as a term to denote the kind of behavior of children described above, the complexity of this term has posed several problems for researchers. One of the first problems in empirical studies has been translating the term from English to other languages. An equivalent word that covers exactly the same meaning is impossible to find. As Smorti and colleagues (2003) observed, some terms are more specific in describing the negative actions of peers toward another peer, while others refer to social exclusion and psychological bullying or to group episodes, and yet others refer to direct physical types of bullying.

In Japan, for example, a largely independent research tradition focusing on ijime has emerged. Morita, H. Soeda, K. Soeda, and Taki (1999) argued that ijime refers more to psychological than to physical aggression, and it is often perpetrated by the whole class against a victim (e.g., by collective ignoring or social exclusion) rather than by one or a few pupils as in situations called bullying elsewhere. In Japan, exclusion and the shunning of a classmate are much more typical forms of bullying than physical and verbal forms.

Bullying in the workplace has been defined by several researchers. For example, Einarsen (1999) contended that "the concept refers to a rather specific phenomenon where hostile and aggressive behaviours, be it physical or non-physical, are directed systematically at one or more 
colleagues or subordinates leading to stigmatisation and victimisation of the recipient" (p. 17). In an earlier definition, Einarsen and his colleagues paid special attention to the imbalance of power in the relationships of the parties, asserting that "[a] person is bullied or harassed when he or she feels repeatedly subjected to negative acts in the workplace, acts that the victim may find it difficult to defend themselves against" (Einarsen, Raknes, \& Matthiesen, 1994, p. 383). Similarly, VartiaVäänänen (2003) employed workplace bullying to specify "a situation in which one or more individuals are subjected to persistent and repetitive negative acts by one or more co-workers, supervisors or subordinates, and the person feels unable to defend him/herself” (p. 11).

In these definitions, scholars agree on three criteria for bullying: 1) It is aggressive behavior or intentional harm-doing, 2) which is carried out repeatedly and over time, 3) in an interpersonal relationship characterised by an imbalance of power. In addition to the researchers and studies already mentioned, the term bullying has been used by different researchers in a large number of studies (e.g., Adams, 1992; Cooper, Faragher, \& Hoel, 2004; Crawford, 1999; Niedl, 1995; Rayner, Sheehan, \& Barker, 1999; Salmivalli, Karhunen, \& Lagerspetz, 1996; Salmivalli, Lagerspetz, Björkqvist, Österman, \& Kaukiainen, 1996; Vartia, 1996; Zapf, 1999).

\section{Mobbing.}

Leymann (1996) recommended bullying as the appropriate term for activities between children and teenagers at school and using mobbing for adult behavior. He argued that much of this disastrous communication among adults does not have the characteristics of bullying. Instead, quite often, adults bully in a very sensitive manner, though still with highly stigmatizing effects. According to Leymann, the connotation of bullying is physical aggression and threat, a characteristic feature for bullying at school. In contrast, physical violence is very seldom found in mobbing behavior at work. Leymann emphasized that mobbing involves much more sophisticated 
behaviors such as socially isolating the victim. According to Leymann, mobbing means "harassing, ganging up someone, or psychologically terrorizing others at work" (p. 165).

Leymann (1996) used mobbing synonymously with psychological terror in working life: Psychological terror in working life involves hostile and unethical communication, which is directed in a systematic way by one or a few individuals mainly towards one individual who, due to mobbing, is pushed into a helpless and defenceless position, being held there by means of continuing mobbing activities. (p. 168)

Although Zapf (1999) employed bullying and mobbing interchangeably, he construed them differently, although not in the same way as Leymann (1996). Zapf treated mobbing as: psychological aggression that often involves a group of 'mobbers' rather than a single person. Theoretically, mobbing is an extreme type of social stressor at work. Unlike 'normal' social stressors, however, mobbing is a long-lasting, escalated conflict with frequent harassing actions systematically aimed at a target person. (p. 70)

In turn, Zapf argued that bullying implies physical aggression by a single person, mostly by a supervisor, which is rare in the working context. Leymann and Zapf agree that mobbing involves less physical aggression and threat than bullying. Recently, however, this kind of distinction between the two terms seems to have fallen away, and the terms have been used synonymously by researchers (e.g., Niedl, 1996; Zapf \& Einarsen, 2001).

\section{Harassment and sexual harassment.}

According to Björkqvist and his colleagues (1994), harassment refers to repeated activities which have the aim of causing mental (sometimes also physical) pain and are directed toward one or more individuals who, for one reason or another, are not able to defend themselves. Quite similarly, by scapegoats, Thylefors (1987) meant one or more persons who, over a period of time, 
are exposed to repeated, negative actions from one or more other individuals. These two definitions stress the same characteristics which are relevant to the various definitions of bullying.

In pioneering work on harassment at work, Brodsky (1976) identified five types of work harassment: name calling, scapegoating, physical abuse, work pressures, and sexual harassment. Brodsky described harassment as repeated and persistent attempts by a person to torment, wear down, frustrate or get a reaction from another person as well as treatment which persistently provokes, pressures, frightens, intimidates or otherwise brings discomfort to the recipient. In contrast to the definitions of harassment presented earlier, Brodsky emphasized the effect of negative behavior on the target. He also specified sexual harassment as one type of work harassment.

In the Scandinavian research tradition, sexual harassment has been examined as a specific form of bullying and work harassment in which sexuality is utilized as a means of oppression, as concluded by Björkqvist and colleagues (1994). While, in the Scandinavian countries, workplace bullying first aroused the interest of researchers (and only afterward became a legal concept representing one of the safety hazards at work), development in the United States was quite the opposite. The concept of workplace harassment developed initially as a legal concept, and subsequently, as an empirical concept studied by social and behavioral scientists. In the federal law of the United States, workplace sexual harassment is considered a form of gender-based discrimination.

According to Pryor and Fitzgerald (2003), two general types of sexual harassment have been distinguished: 1) unwelcome sex or gender-related behavior that creates a hostile environment, and 2) "quid pro quo" behavior, where the unwelcome behavior becomes a term or condition of employment or advancement. They explained that, in the legal analysis of sexual harassment, sexual coercion often constitutes "quid pro quo" sexual harassment, where sexual or gender-related behavior comprises a term or condition of employment or advancement. Unwanted sexual attention 
and gender harassment often constitute what is termed hostile environment sexual harassment, where the sexual or gender-related behavior creates an intimidating, offensive or hostile work environment. It may be argued that unwanted sexual attention constitutes a form of quid pro quo sexual harassment, if toleration of such behavior becomes a term or condition of employment (Fitzgerald, Gelfand, \& Drasgow, 1995). According to Pryor and Fitzgerald, gender harassment comprises the most common form of sexually harassing experience, followed by unwanted sexual attention and then by sexual coercion.

The legal understanding of sexual harassment in the United States focuses upon potential employment consequences for victims. Sexual harassment is illegal because it represents a potential barrier to equal employment. Whether the perpetrator intends the behavior to be offensive or not is not the issue, according to the law. The main consideration includes the incident unwelcome behavior. Perspectives of unwelcome sexual or gender-related behaviors obviously vary from person to person and across circumstances. Perhaps the crucial feature distinguishing sexual harassment from bullying is that plaintiffs in sexual harassment law suits in the United States must prove that the harassment is somehow based upon gender (Pryor \& Fitzgerald, 2003). (For a review of the research on sexual harassment, see, for example, Fitzgerald \& Shullman, 1993; Kreps, 1993.) Finally, it should be noted that a growing area of research in the United States focuses especially on sexual harassment established at school. Batsche and Knoff (1994), for example, have paid attention to sexual harassment in their definition of bullying at school. In the European tradition, sexual harassment at school has usually not been distinguished as a concept, but instead, the various forms of sexual harassment have been included in the concept of school bullying in the sense of name-calling, physical harassment, or insulting remarks concerning one's physical appearance, for example.

\section{Characteristics of Bullying at School and in the Workplace}


In the following pages, we compare the main characteristics of the concepts reviewed thus far and identify their most visible similarities and differences. Most definitions include common features of bullying, both at school and in the workplace, but in some respects, scholars treat the concept of bullying differently in school contexts and in working-life contexts.

\section{The nature of hurtful behavior.}

In most of these definitions, bullying, mobbing, and harassment are depicted as negative behaviors directed at the target. However, while the direct forms of bullying seem to be clearly established in the existing definitions as negative acts, negative actions, aggressive behavior, a form of aggression, hostile and aggressive behavior, deliberate hurting and frightening, and hostile and unethical communication, the indirect forms of this behavior have rarely been noticed explicitly at the definitional level. Indirect bullying (e.g., social exclusion and the spreading of rumors) is not addressed directly to the target; the target might be totally unaware that this kind of behavior is taking place. Yet, indirect forms of bullying can be even more hurtful and long-lasting than direct forms because, in the case of indirect bullying, the victim might not even be afforded any logical situations to stand up and defend him or herself. Although the victim clearly experiences the consequences of bullying, he or she might not even know the identity of his or her most influential bully or bullies. However, also in these cases, the role of victim is created and maintained by means of communication, which could be explicated in the definition of bullying.

In the school context among children and adolescents, empirical studies have shown that bullying behaviors include both physical (e.g., hitting, kicking, and pushing) and verbal (e.g., shouting, threatening) as well as direct (i.e., directly addressed at the target) and indirect (e.g., spreading of rumors, social exclusion) forms of violence and hurtful communication (e.g., Olweus, 1993; Salmivalli, 1998; Sharp \& Smith, 1991). In work contexts, bullying consists of negative and hurtful verbal messages, both direct and indirect forms of bullying, as well as various kinds of 
work-related activities designed to hamper the target in the performance of his/her duties, whereas the various forms of physical violence do not usually occur in the work environment (e.g., Björkqvist et al., 1994; Einarsen \& Raknes, 1997; Meek, 2004; Vartia, 1993). Hence, empirical findings suggest that the characteristics of bullying become more sophisticated when moving from school to working life. However, this developmental course cannot be traced in the definitions of bullying.

Further, very exceptionally, Leymann (1996) defined mobbing as hostile and unethical communication. As communication scholars, we would, with pleasure, move the focus from negative acts and aggressive behaviors more specifically to the negative and hurtful communication which seems to be the most typical form of bullying both among children and adults. The various forms of communication in bullying situations can be unintentionally ignored by researchers if they ask respondents to describe and evaluate the negative acts or behaviors of which they have been targets. The definitions of bullying should explicitly include negative and hurtful communication which is either directed toward the target or has significant reference to him or her, as in the case of indirect bullying.

Finally, instead of being examined only as the behavior of one person or a few persons directed toward another person/persons, bullying should rather be examined as a communication relationship between bully/bullies and victim/victims and, as such, be envisioned as an ongoing interaction process consisting of a continuous flow of exchanging and appraising messages. The nature of a bullying relationship changes all the time according to the outcomes of this interaction. The parties involved in this interaction process (bully/bullies, victim/victims, and bystanders) have a significant role in changing the course of the bullying relationship. Definitions of bullying should recognize the relational nature of this phenomenon.

The frequency and duration of hurtful behavior. 
The terms bullying (e.g., Batsche \& Knoff, 1994; Einarsen, 1999; Hoover et al., 1992; Olweus, 2003; Smorti et al., 2003; Vartia-Väänänen, 2003), mobbing (e.g., Leymann, 1996; Zapf, 1999), and harassment (Björkqvist et al., 1994; Brodsky, 1976) all refer to negative behavior which is repeated, persistent and long-term. Hence, these definitions do not include occasional aggressive or insulting behavior either in the context of school or workplace. The concept of mobbing offered by Leymann, for example, excludes temporary conflicts and focuses on a point in time where the psychosocial situation begins to result in a psychiatrically or psychosomatically pathological condition. Thus, he considered the distinction between conflict and mobbing to be a question not of what is done or how it is done but of the frequency and duration of what is done. Leymann even provided statistical indicators for frequency and duration by determining that, in order to be classified as mobbing, hurtful activities need to occur on a very frequent basis (statistical indicator: at least once a week) and over a long period of time (statistical indicator: at least six months).

Adherence to a temporal criterion has been criticized particularly in the school context. Ross (1996), for example, argued that it is not in the best interests of effective management of bullying, because interventions should be introduced at the earliest point, when it is easiest to stop the bullying and the least damage has been caused to the victim. Our suggestion is, however, that we reserve the terms bullying and mobbing to determine the repeatedly occurring hurtful behavior and use labels such as aggressive behavior and hurtful communication to refer to occasional insulting and unethical behavior directed at a target. We want to emphasize that, in a practical sense, any hurtful incident between pupils requires intervening as soon as it occurs, in order to prevent bullying relationships from developing.

While sexual harassment can also represent a pattern of behavior in the workplaces where it exists, single episodes of behavior may cross a threshold of severity so as to be considered sexual harassment in a legal sense, particularly in instances of blatant "quid pro quo" sexual harassment 
(Pryor \& Fitzgerald, 2003). Hence, sexual harassment makes an exception to the criterion of repetition.

The imbalance of power between the parties.

An obvious imbalance in the power relationships between the parties has been clearly emphasized in the definitions focusing on bullying at school (Hoover et al., 1992; Olweus, 2003; Peterson \& Rigby, 1999) as well as the work environment (e.g., Einarsen et al., 1994; Hoel \& Cooper, 2001; Leymann, 1996; Vartia-Väänänen, 2003). Olweus, for example, stressed that bullying requires an imbalance in strength (an asymmetric power relationship), which means that the student who is exposed to the negative actions has difficulty in defending himself or herself and is somewhat helpless against the student or students who harass. Similarly, Naylor and Cowie (1999) characterized bullying as being based on the systematic abuse of power. It is typified by the bully's and victim's inequality of access to power. As such, bullying does not occur when two school children of about the same strength have the odd fight or quarrel (Peterson \& Rigby, 1999), nor should a conflict situation where an equal balance of power exists between the employees involved be regarded as bullying, mobbing or harassment.

Among children, the imbalance of power might result from the target of the bullying actually being physically weaker, or he or she might simply perceive himself or herself as physically or mentally weaker than the perpetrator. Imbalances could also encompass a difference in numbers (with several students ganging up on a single victim) or when the "source" of the negative actions is difficult to identify or confront (as in the cases of social exclusion from a peer group, talking behind the victim's back, or sending anonymous mean notes) (Olweus, 2003).

In the workplace, the imbalance of power might originate from an individual's hierarchical position within the organization or society, experience and previous knowledge, or personal 
contacts. Hoel and Cooper (2001) presumed that knowledge of an opponent's vulnerabilities could also be a source of informal power.

Hence, the imbalance of power constitutes one of the clearest characteristics of bullying both at school and in the workplace, but the sources of power differ between children and adults. Among children, perceived or anticipated physical predominance and the inability of the victim to defend him/herself are the most obvious sources of the imbalance of power, whereas professional status likely plays a significant role as a source of power differences among adults at work. As communication researchers, we would consider differences in communication skills between the parties as well as the communication networks of individuals to be further sources of power both at school and in the workplace.

\section{Intentionality and interpretability of hurtful behavior.}

The intentional attempt of a bully to hurt and cause harm to his or her target remains central to the concept of school bullying (e.g., Hoover et al., 1992; Olweus, 2003; Peterson \& Rigby, 1999). Olweus stated that "[a]lthough children or youth who engage in bullying very likely vary in their degree of awareness of how the bullying is perceived by the victim, most or all of them probably realise that their behaviour is at least somewhat painful or unpleasant to the victim" (p. 62).

In the concepts of workplace bullying, on the other hand, intentionality becomes more problematic. Scholars disagree concerning the usefulness of including intentionality in the defining characteristics. For example, the behavior of a person considered as a bully might not always be meant to harm the target, but the experience of having been bullied might be formed as a nonintended side effect of this behavior (Hoel \& Cooper, 2001). Similarly, Einarsen (1999) argued that hurtful actions can be performed either deliberately or subconsciously, but they clearly have 
negative consequences for the target. Hence, the hurtful behavior might sometimes be intended to be hostile, but, in some cases, it might merely be perceived as hostile by the recipient.

Further, according to Leymann (1996), hostile activity consists of quite normal interactive behaviors to a great extent, but when they happen very frequently and longitudinally in order to harass, their content and meaning change, consequently turning them into dangerous, communicative weapons. Hence, their systematic use in this type of interaction triggers the development of the mobbing process.

Scholars emphasize that the definitional core of bullying at work rests on the subjective perception made by the victim that the repeated acts are hostile, humiliating and intimidating and that they are directed at himself/herself, and the subjective experience of being bullied can manifest itself in mental and physical health problems (e.g., Einarsen, Raknes, Matthiesen, \& Hellesöy, 1996). According to this view, being exposed to a behavior that can be construed as bullying is not harmful if the recipient does not perceive it as such. On the other hand, however, Cooper and colleagues (2004) asserted that becoming a target of bullying, independent of whether participants label the experience as bullying or not, has a considerable detrimental effect on targets, seriously affecting their health and well-being.

In the concept of sexual harassment, intent has mostly been excluded as a defining feature (Pryor \& Fitzgerald, 2003). Therefore, the subjective interpretation of the target as having been sexually harassed is enough to determine a hurtful behavior as sexual harassment.

To conclude, intentionality and interpretability of the behavior or communication of an individual constitute critical issues when defining and examining bullying. It seems contradictory that children, who are usually less conscious of their communication behavior than adults, are presumed by researchers to be aware of the harm that they cause to the victim by bullying (e.g., Hoover et al., 1992; Olweus, 2003; Peterson \& Rigby, 1999), whereas adults are presumed to be not necessarily conscious of their bullying behavior (e.g., Einarsen, 1999; Hoel \& Cooper, 2001). The 
explanation of this contradiction lies in the different forms taken by bullying among children and adults. The physical and verbal forms of bullying directly addressed to the target (e.g., hitting, pushing, shouting, and threatening the target) which have been shown in empirical studies to be typical of children at school may be easily recognized and identified as bullying even by children. These acts cannot be undertaken without a conscious design to hurt the target. Instead, the indirect and work-related forms that characterize bullying among adults at work (e.g., criticizing or ignoring the victim's work or ideas, giving feedback in a hurtful manner, or excluding someone from the social group to which he or she should belong), as well as the various forms of sexual harassment and the harm that these behaviors cause to the victim, are much more difficult to perceive and label as bullying, even though the target of this behavior clearly experiences harassment. This kind of hurting can be either intentionally or unintentionally produced.

However, we think that paying more attention to the indirect forms of school bullying, both conceptually and empirically, might show that indirect bullying is as typical as direct bullying among pupils. Instead of expressing power (as in the cases of direct bullying), the forms of indirect bullying (e.g., spreading rumors or socially excluding someone from a group) basically function constructively in the processes of establishing interpersonal relationships and group structuring, as we detail later in this chapter. As such, these processes could be positive for most of the individuals involved, but, for those who are used as "tools" to serve others' social goals, they become destructive. Bullying, which is produced as a "side-effect" of these processes, might often be unconsciously generated.

The definitions given to bullying at school reflect more general tendencies, such as paying attention to easily observable forms of bullying (see, for example, Batsche \& Knoff, 1994; Hoover et al., 1992; Olweus, 2003; Peterson \& Rigby, 1999; Smorti et al., 2003), whereas the studies of workplace bullying and sexual harassment (and the concepts used to refer to these phenomena) focus mainly on the victim's subjective experience of having been bullied (e.g., Brodsky, 1976; 
Einarsen et al., 1994; Pryor \& Fitzgerald, 2003; Vartia-Väänänen, 2003). The subjective experience of the victim always extends from interpretations given to others' behavior by the victim. This fact emphasizes the need to examine the interpretative nature of communication in bullying situations, which will be discussed more closely in the following sections.

\section{The Prevalence of Bullying at School and in the Workplace}

The hurtful and abusive behavior described in the previous section unfortunately occurs commonly both at school and in the workplace. In this section, we examine the general prevalence of bullying at school and in the workplace in different cultures, and we then move on to identify the bullies and their victims, according to differences in gender and organizational status.

Although the ways in which school bullying is defined and assessed vary across individual studies, thus making direct comparison of results difficult, $5-20 \%$ of school children have been reported to be victims of repeated bullying (see, for example, Björkqvist, Ekman, \& Lagerspetz, 1982; Espelage \& Holt, 2001; Kannas \& Brunell, 2000; Kannas, Välimaa, Liinamo, \& Tynjälä, 1995; Lagerspetz, Björkqvist, Berts, \& King, 1982; Olweus, 1993, 2003; D.G. Perry, Kusel, \& L.C. Perry, 1988; Rigby \& Slee, 1991; Salmivalli, Lagerspetz, et al., 1996; Whitney \& Smith, 1993). About the same percentage of pupils usually report acting as bullies on a weekly or more frequent basis (Olweus, 1999; O’Moore, 1989; Rigby, 1997; Smith \& Sharp, 1994; Vikat, 1998). Bullying likely decreases in the upper grades, with the highest incidence occurring in grades 5 to 9 (corresponding to ages 11 to 15, approximately) (Espelage \& Holt, 2001; Smith \& Madsen, 1999). According to Espelage and Holt, boys self-report more bullying and are also nominated as bullies more often than girls.

The proportion of children involved in bullying in primary schools, either in the role of bully or that of victim, or both, fluctuates from $41 \%$ in Italy to $27 \%$ in England, $20 \%$ in Portugal, $18 \%$ in Spain, $11 \%$ in Japan, and 9\% in Norway, in studies conducted in these countries using 
similar methodologies (see Smith et al., 1999). Based on their study of retrospective data collected from adolescent students, Hoover and colleagues (1992) concluded that victimization by bullies can be even more prevalent in the United States than in European countries, perhaps as a function of the overall higher rate of violence in the United States. In their study, 76.8\% of the respondents reported experiencing bullying at some point in their student careers. However, Smorti and colleagues (2003) suggested that, rather than indicating cultural differences in the prevalence of bullying, varying frequencies between studies more likely reflect the variety of the meanings given to bullying by respondents in different cultures and languages.

At work, bullying is as widespread a problem as it is at school. A study conducted in Great Britain by Hoel, Cooper, and Faragher (2001) revealed that $10.6 \%$ of the respondents $(\mathrm{N}=5,288)$ had been bullied within the preceding six months. The number increased to $24.7 \%$ when the respondents were asked about having been bullied within the last five years. Additionally, $46.5 \%$ reported indirect experiences of workplace bullying (i.e., having witnessed or observed bullying) within the previous five years. Another study demonstrated that as many as $53 \%$ in a sample of 1,137 part-time students at an English university reported that they were bullied at work (Rayner, 1997).

In Scandinavian countries, similar frequencies have been reported. In a study of Norwegian employees $(\mathrm{N}=7,986)$ representing a broad array of organizations and professions, $8.6 \%$ had experienced bullying and harassment at work during the preceding six months (Einarsen \& Skogstad, 1996). In a study conducted in Sweden, using a scale on which bullying was operationalized as exposure to any one of 45 predefined negative acts on a weekly basis for more than six months, $3.5 \%$ of a representative sample of the working population were found to be victims of bullying at work (Leymann, 1992).

Further, in a survey of Finnish university employees (N=726), $24 \%$ of females and $17 \%$ of males were regarded as victims of harassment at work (Björkqvist et al., 1994), and among the 
personnel of Finnish health-care units (N=984), Vartia (1991) determined $10 \%$ of respondents to be victims of bullying. According to the latest Working Condition Survey conducted in Finland, as many as $22 \%$ of 4,000 respondents claimed to be (or have been) a target of bullying in the workplace (Lehto \& Sutela, 2004).

Similarly, among the employees of an Australian public hospital, $26.6 \%$ reported that they had been subjected to one or more hostile acts once a week during the preceding six months (Niedl, 1995), and in a survey of 806 employees at an American university, $23 \%$ revealed mistreatment during the previous 18 months (Spratlen, 1995).

Although these studies suggest some cultural differences in the prevalence of workplace bullying, variance in definitions and measurement and types of samples employed make national comparisons difficult, as Einarsen (2000) emphasized. However, bullying at work has clearly been established as a serious problem at workplaces in all of the examined countries.

Some cultural differences, however, emerge regarding the prevalence of sexual harassment at work. More than half of all Finns, for example, suffer from it at some point in their lives (Heiskanen \& Piispa, 1998; Melkas, 2001). Investigations in the United States indicate very similar numbers of victims (Einarsen, Raknes, \& Matthiesen, 1993). However, in a survey focusing on cultural differences, Norwegian women working in male-dominated industrial organizations were exposed less to recurrent unwanted sexual attention (27\%), compared to American women in a similar situation (60\%). Further, while $36 \%$ of the American women reported being victims of sexual harassment, only $5 \%$ of Norwegian women disclosed the same experience (Einarsen \& Sørum, 1996). This difference has been attributed to the androgynous sex-roles and feminine values more characteristic of Norwegian than of American culture (Einarsen, 2000).

Previous research conducted in several countries indicates that the majority of bullies tend to be individuals with organizational authority who hold superior positions relative to their victims (e.g., Hoel et al., 2001; Lutgen-Sandvik, 2003). However, Scandinavian studies suggest that the 
number of superiors and peers perceived to be bullies are approximately equal (Einarsen \& Skogstad, 1996; Leymann, 1992). Further, based on a study investigating bullying among business professionals holding predominantly managerial or expert positions, Salin (2001) concluded that individuals in managerial positions are also likely to be bullied. Of those classifying themselves as managers, $2 \%$ had experienced bullying during the previous 12 months, whereas $9.6 \%$ of middle managers, $7.2 \%$ of experts, and $17.5 \%$ of officials/clerks experienced bullying during the same time period. According to Salin, the percentage of victims was significantly higher among female than among male managers and experts, and the percentage of bullied female managers was higher than the percentage of bullied females in other positions.

Concerning gender differences, data from surveys of 7,986 Norwegian employees within 13 different organizational settings exhibited no difference in the prevalence of bullying among men and women (Einarsen \& Skogstad, 1996). The British male workers surveyed by Hoel and colleagues (2001), however, were more likely to be bullied than women, but this finding was reversed in the study of middle and senior management. Of the female senior management, $15.5 \%$ reported having been bullied, just about twice as many, in percentage terms, as the male managers. Based on this research, women become more vulnerable to negative behaviors as they progress through the organizational hierarchy and penetrate the hierarchical barriers. Men who feel threatened by women might use bullying to exclude women from the higher positions (Davidson \& Cooper, 1992; Veale \& Gold, 1998).

These findings indicate that gender and organizational status do explain the division of bullies and victims, to some extent. While boys take the role of bully more often than girls in peer groups at school, no clear gender differences have been identified among employees working at the lower levels of organizational hierarchy. However, women with more organizational authority become more vulnerable to bullying than men in corresponding positions. 
These findings emphasize the need to examine the issue of power in bullying incidents. Who has the power in bullying relationships, and how is this power communicated? How is power achieved, and how is it revealed in the relationship. How is it distributed in the group and the organization in which bullying occurs? What is the role of communication in the processes of the distribution of power? What kind of communication is used to increase or decrease the power differences between individuals? Can power (e.g., the professional power of a female manager) be neglected or ignored in the interaction of individuals involved in bullying? Finding answers to these questions would be important in order to promote the development of impartial communication relationships at school and in workplaces.

Another issue arising from the findings described above underscores the role of cultural learning. In socialization processes, children learn and adopt from their parents, and particularly in their peer groups, such behavior which is characteristic of their gender in their own culture (e.g., Harris, 1995). If girls at school and women with more organizational authority are more vulnerable to bullying than boys and men in the same circumstances, then we should examine the kind of gender-related communication expectations and norms that direct our behavior at school and in the workplace, the way in which they relate to bullying, and how they are taught and shared in society.

\section{Processes of Bullying as the Exchange and Appraisal of Messages}

In this section, we explore bullying as a communication process consisting of the exchange of hurtful messages delivered by the bully and strategies of defense produced by the target. Both of these components have been researched, but their connections to each other in actual communication situations have not been demonstrated. In this section, we stress the need for future communication studies to focus on these connections and, in so doing, on the interaction processes and communication relationships in which bullying appears. We begin with a review of investigations that describe characteristics of hurtful messages and various strategies of defense, 
and we conclude the section by offering some ideas as to how future studies might profitably approach bullying as a communication process.

\section{Hurtful Messages}

Bullying among children and adolescents at school occurs in many different forms, as we already demonstrated in the discussion concerning the defining of bullying. It can be direct or indirect. Scholars consider bullying to be direct when it includes fairly open attacks directed against the victim. Direct forms of bullying include various kinds of physical violence (such as kicking, beating, and pushing) and assorted verbal attacks, such as insulting, name-calling, and threatening. Coercion, blackmail, and the destruction of the other student's work also comprise forms of direct bullying (Olweus, 1993). Name-calling, denigration and threatening are the most common forms of bullying among both boys and girls (Salmivalli, 1998).

Indirect bullying takes forms like isolating someone from the group, spreading rumors and revealing secrets (Olweus, 1993; Salmivalli, 1998). A person using strategies of this kind to hurt might not be punished for his or her actions because indirect bullying is not easy to identify. Previous research has reported a general decline in direct, physical bullying with increase in age/grade, while the level of verbal harassment remains constant (Perry et al., 1988).

Most previous empirical research suggests that, while boys more often resort to physical and verbal attacks and threats than girls, girls tend to prefer more subtle and indirect ways of bullying, such as slander, or manipulating others to make them avoid talking to or playing with the victim (Björkqvist, Lagerspetz, \& Kaukiainen, 1992; Olweus, 1978, 1993; Rigby, 1997; Salmivalli, Kaukiainen, \& Lagerspetz, 2000; Sharp \& Smith, 1991). However, conflicting results concerning gender differences in the aggressive behavior of children and adolescents have also widely been reported (for a discussion of these conflicting findings, see, for example, Salmivalli \& Kaukiainen, 2004; Underwood, Galen, \& Paquette, 2001; Underwood, Scott, Galperin, Bjornstad, \& Sexton, 
2004). Explanations for these contradictory findings can be attributed to differences in participant age, sample sizes, methods and measurement scales, and cultural characteristics of communication. Expectations concerning the expression of aggression by females and males may vary from one culture to another, encouraging males and females to move in the same direction in one culture and in different directions in another culture. Notably, patterns of behavior do change with time, which can be seen, for example, in some Western cultures where the frequency of physical violence demonstrated by girls has clearly increased (Lagerspetz, 1998).

Although different researchers vary in their classification of the forms of bullying at work (see e.g., Björkqvist et al., 1994; Einarsen \& Raknes, 1997; Hoel et al., 2001; Keashly \& Jagatic, 2003; Meek, 2004; Vartia, 1993), similar types of direct, indirect, and work-related harassment have been identified in several studies. The methods of harassment that occur at work very much resemble those occurring at school, although the former tends to be more sophisticated, including more developed enactments of indirect bullying. Indeed, the most common forms of aggression at the workplace have been reported to be indirect in nature (Björkqvist et al., 1994) and encompass different kinds of harassing work-related activities.

Just as with school bullying, the direct forms of bullying at work range from intimidation (Einarsen \& Raknes, 1997; Hoel et al., 2001) to threats or acts of physical violence (Meek, 2004; Vartia, 1993). However, more typical types of direct bullying include verbal utterances such as insulting or offensive remarks (Hoel et al., 2001; Meek, 2004), personal derogation, humiliation and personal criticism (Einarsen \& Raknes, 1997), accusations (Björkqvist et al., 1994), and insinuations about a person's mental state (Vartia, 1993) or personal life (Björkqvist et al., 1994).

Like the forms of bullying which occur at school, the forms of indirect bullying in the workplace span social exclusion (Einarsen \& Raknes, 1997; Meek, 2004), slander (Vartia, 1993), the spreading of rumors (Björkqvist et al., 1994; Hoel et al., 2001; Vartia, 1993), and "the silent treatment" (i.e., shunning; Björkqvist et al., 1994; Meek, 2004). However, work-related forms of 
harassment, such as the withholding of information, causing work overload, or having one's responsibilities removed (Einarsen \& Raknes, 1997; Hoel et al., 2001; Meek, 2004; Vartia, 1993), and continuous criticism of people's work and its results (Björkqvist et al., 1994; Hoel et al., 2001; Vartia, 1993) occur most typically in work contexts. Commonly, targets of bullying at work have limited opportunities to express themselves or influence their tasks or be taken seriously or listened to (Björkqvist et al., 1994). Pupils at school might also confront such constraints, but no empirical evidence exists to support such a claim.

Keashly and Jagatic (2003) demonstrated the multifaceted nature of bullying by summarizing the research results of several scholars and proposing a distinction between verbal and physical aggression in the workplace, between the directness or indirectness of the behavior, and the activeness or passiveness of the behavior in question. Name-calling, insulting jokes and yelling are examples of active, direct and verbal aggression occurring in the workplace. The indirect version of this active aggression could be false accusations and the spreading of rumors. Passive ways to directly and verbally affect the target include ignoring and silent-treatment. With indirect verbal behavior, the aggression manifests itself when the person is excluded from the necessary workrelated information in several ways. Aggression in the workplace can also take physical, active and direct forms when the target is exposed to physical assaults and harassment (e.g., sexual, racial). Indirectly, the physical assault can be directed to, for example, the property of the target. Also, work overloading can be construed as an active physical assault, yet an indirect form of that assault. However, the severe attempts to sabotage the targets' possibilities to do their tasks by cutting the resources necessary or offering impossible resources can be perceived as passive and indirect physically aggressive behaviors.

Research findings hint at some cultural and situational variation in the forms of bullying, although this issue has not been systematically examined. In Japan, for example, where the prevalence of workplace bullying dramatically increased in the early 1990s, victims reported 
extremely destructive forms of bullying, such as being a target of physical violence, having superiors and peers refuse to talk to the victim or greet him or her, not being allowed to attend meetings or receive memos, having office furniture and equipment taken away, being required to do excessively late and all-night work, and sexual harassment (Meek, 2004). As interpreted by Meek, this trend corresponded with the economic crisis faced by Japan in the 1990s; the purpose of workplace bullying was to drive out employees without technically violating the lifetime employment principle characteristic of Japan.

The comparison of bullying experiences at different organizational levels illustrates the fact that workers are exposed to insults or offensive remarks and excessive teasing more often than managers. Managers, however, disclosed exposure to unmanageable workloads and unreasonable deadlines more frequently than workers (Hoel et al., 2001).

Kinney (2003) categorized sexual harassment messages into five groups according to the theme of the message: 1) hostile and aggressive sexual demands (statements that include sexual demands, often using vulgarities and threats, 2) sexual condescension (statements that disparage the intellect or competence of the recipient), 3) sexual desirability and undesirability (statements that refer to the sexual potential of the recipient), 4) sexual willingness and readiness (statements that make reference to the perceived sexual willingness of the recipient), and 5) sexual dissection/objectification (statements that referenced specific aspects of the recipient's body that was sexualized). In a research interview conducted by Ryynänen (2003), ten sexually harassed women reported that their experiences of sexual harassment were based, not only on the meanings carried by the verbal messages of the harasser, but also on the appraisals and interpretations given to nonverbal messages (e.g., tone of voice, use of silence, facial expressions, use of gaze or smile, physical distance between communicators, and touching), the personality of the harasser, his/her expected intentions in the communication situation, and his/her responses to the target's signals of 
rejection. Hence, perceived sexual harassment may be based, not only on the harasser's communication behavior as such, but also on the interpretations given to this behavior by the target.

To summarize, previous research has clearly demonstrated the multiplicity of the forms of bullying. It has also revealed various ways in which communication is involved in bullying, either in the form of messages directly addressed to the target or concerning his or her work or personal affairs, or as interaction which hinders the target's ability to perform his or her tasks in a desirable manner, or to make it more difficult for him or her to establish good relationships with colleagues or peers. However, we do not know much about the interaction processes in which bullying messages are produced and interpreted, with or without the parties being simultaneously present.

In the target's evaluation of the significance of negative acts directed at him or her, the target presumably tries to understand the reason why he or she has been chosen as a target and estimate his or her chances of preventing the bully from proceeding. The target could possibly find the reason for bullying in the characteristics or behavior of him/herself or in those of the bully, the relationship of the parties, or the interaction which has taken place between them. Potentially, the target can then use this interpretation in the production of his or her self-defense.

\section{Strategies of Defense}

When a person feels that he or she has been attacked or victimized by individuals with whom s/he shares a substantial part of his/her daily life, s/he must choose how to respond to this abuse and how to defend him/herself. Previous research indicates that victims of bullying employ a variety of defensive strategies to survive.

According to Salmivalli, Karhunen, et al. (1996), the victims of school bullying tend to use three different kinds of strategy to defend themselves. These strategies include aggression, trying to show that one doesn't care about the bullying, and being hurt/helpless behavior. Children who use aggression as a strategy to cope with bullying try to hit back as hard as needed. Pupils who try not 
to care about the whole situation attempt to stay calm and avoid showing any interest in the bullying acts being performed. Helpless victims, rather than face the bully, strive to escape from the critical situation. Their response is to exhibit their powerlessness. It should be noted that these categories only describe the observable behavior of the victims, not their subjective feelings or thoughts.

Further, Smith, Talamelli, Cowie, Naylor, and Chauhan (2004) coded the coping strategies reported by pupils into seven discrete categories: 1) talk to someone (teacher, counselor, parents, tutor), 2) ignore the bullying, 3) stick up for yourself (take care of myself, get more mature, sort it out with bully), 4) avoid, stay away from the bully, 5) get more and different friends, make an effort to become more popular, 6) fight back, and 7) different behavior / attitude (try to be happier, behave normally, mind my own businesses, don't cry). Overall, the most common strategy was talking to someone about bullying. However, the escaped victims (i.e., those who had been, but no longer were, bullied) more frequently reported disclosing talking to someone about the bullying and trying to have more or different friends and be more popular, whereas those who had not managed to escape from the bullying more often reported trying to ignore the bullying.

Research suggests that defensive acts in bullying situations improve when children get older. Younger pupils more likely react to bullying by crying. Defensive strategies get more complex with age, and, for example, not paying attention to bullying becomes a more common defensive strategy. (Smith \& Madsen, 1999.) Crick and Dodge (1994) also contended that, as children age, their ability to perceive social information, produce more complex responses, and enact strategies improves. If the improvement of defensive acts further continues in adulthood, we can assume that the strategies used by adults in cases of workplace bullying are quite welldeveloped.

In studies of bullying at work, the term coping has usually been used instead of strategies of defense when referring to the efforts made by the victim in bullying processes. Coping refers to the “constantly changing cognitive and behavioral efforts to manage specific external and/or internal 
demands that are appraised as taxing or exceeding the resources of the person" (Folkman \& Lazarus, 1984, p. 141). Hence, coping in bullying processes can be regarded as including the behavioral strategies of defense used by the victim in actual bullying situations as well as the cognitive efforts of the victim to master or overcome bullying.

In their interviews of bullying victims, Zapf and Gross (2001) identified four conflict management strategies. The exit category includes active behavior that might at the same time be regarded as destructive, since, in bullying cases, exit behavior often means, for example, the ultimate solution - quitting the job. On the other hand, for the victim, leaving a difficult working environment is not necessarily a destructive thing. The voice category refers to active and constructive problem-solving behavior, and the loyalty category consists of the silent and passive hope that the problem will be solved. The fourth strategy is neglect, referring to passive and thus destructive behavior such as reduction of commitment to the working organization. Zapf and Gross found that most of the bullying victims changed their strategy several times during the bullying process.

Several other researchers have examined the coping strategies used by the victims in bullying processes at work (e.g., Alberts, Lutgen-Sandvik, \& Tracy, 2005; Hogh \& Dofradottir, 2001; Niedl, 1996; Zapf \& Gross, 2001), getting similar results regarding the developmental courses of these strategies. Very often, victims of bullying faced with a conflict situation start off with a more active and constructive strategy (e.g., advancing arguments against the accusations of the bully or openly talking about the distressing situation with him or her). If this strategy fails to succeed, victims tend to change their behavior, and the majority avoid conflicts, if possible. One way of trying to avoid conflict is to adapt to the other party and give up one's own interests. Even this approach is not always a successful strategy, and thus, most victims end up trying to escape the conflict or to direct their efforts toward becoming "invisible." According to Zapf and Gross, leaving the organization and seeking support are the strategies most often recommended by bullying victims to other 
bullying victims. However, seeking support by making a complaint against the perceived bully, for example, can be regarded by the bully as provocative or hurtful behavior, which, in turn, can result in the escalation of the conflict and lead to a situation which the victim cannot control.

With regard to sexual harassment, Clair (1993) concluded that women do not openly complain about sexual harassment because organizations rarely encourage open discussion of this issue and prefer confidentiality when dealing with complaints. Further, Clair suggested that women avoid going through formal channels to report sexual harassment because they expect (and fear) that their complaints could be ignored or trivialized and that they may face a lack of protection from future retaliation as well as opposition from the male dominated hierarchy. Hence, their time will be wasted because of the ineffective sexual harassment policy of the organization. Instead, they choose to avoid or escape conflicts with their harasser and to discuss harassment only with their family members or best friends.

Even talking to one's family members about sexual harassment can be difficult in some cultures. In Malay societies, for example, women avoid reporting sexual harassment incidents to their fathers and brothers, out of fear that they would be accused of having invited the harassment by being insufficiently reticent and modest, or that, by reporting these incidents, they would obligate their male family members to react aggressively (e.g., by taking a revenge to the harasser) to being shamed by the harassment of their female family members (Collins \& Bahar, 2000).

To summarize, on the basis of previous research, we already know something about the kinds of defensive or coping strategies victims choose in bullying processes. However, we do not know why victims choose a particular strategy, what factors direct the selection of the strategy, or what the possible consequences of different strategies might be for the bullying. To increase understanding of why the processes of interaction sometimes lead to a situation where the victim finds it difficult to defend him/herself, growing attention should be paid, not only to the forms of bullying, but also to the intensity of hurtful messages and the communication strategies used in 
bullying as well as to the relationship between hurtful communication and the characteristics of the strategies of defense.

Communication research offers initial insight as to how these questions might be approached. For example, Kinney (1994) provided a model for the classification of hurtful messages. By means of this model, verbal attacks can be described as based on conscious selection of the power and content of the attack as well as on the method of delivering it. Our assumption is that the bully can choose how deeply he or she wants to hurt the target by varying these elements. In addition to taking advantage of this variation, the bully might construct and argue his or her verbal attack so skillfully as to make it almost impossible for the victim to respond and for an outsider to identify it as an attack. For group members, the insults are usually easier to interpret because the hurtful messages extend from meanings shared within the group. A skillful bully can identify these shared meanings, although the victim might be unaware of them. The bully may also be adept at resisting possible defensive acts of the victim. Hence, although the victim may try to respond to hurtful messages with the same intensity, responses can be deterred because of the well-developed strategies used by bully.

The concept of face can be traced back for centuries into Chinese culture (e.g., Ho, 1976; Hu, 1944), and the theory of face work (Goffman, 1967) provides a further tool for analyzing the relationship between hurtful messages and the strategies of defense. Brown and Levinson (1987) defined the concept of face (which they derived from the work of Goffman) as "the public selfimage that every member wants to claim for himself' (p. 61). According to Cupach and Metts (1994), the theory of face work is useful in challenging, threatening, paradoxical, difficult, or awkward situations. While speakers usually base interaction upon respect and the preference for mutual face preservation, in bullying situations, the interaction involves hurting and threatening the partner's face. Bullying can certainly be regarded as a face threat to the target, and in order to save or return his or her face, the target must engage in defensive and protecting acts. Hence, we should 
investigate the possibility that the defensive strategies chosen by the victim will be related to the threat of face experienced by him or her.

Further, interpretations of (and the different kinds of clues used to identify) hurtful communication can trigger specific defensive responses. The Social Information-Processing model, introduced by Crick and Dodge (1994), clarifies children's creation of behavioral enactment in situations where social adjustment is needed. Crick and Dodge found that aggressive children more likely interpret other's intentions as deliberately hostile and concentrate more on aggressive clues. Aggressive children also generate more hostile strategies and goals than prosocial children, and they tend to believe that the use of aggression can lead to positive outcomes. Suggesting that personal characteristics direct defensive strategies, this research invites further investigation in order to determine the various interpretations made of others' communication behavior and the strategies generated on the basis of these interpretations by individuals with different kinds of personal characteristics (e.g., shy or reticent, assertive, and supportive individuals).

On the other hand, from the victim's perspective, a bullying relationship can be examined as an unwanted relationship in which the bully is the stronger party and the victim is always the clear loser of the exchange. Hess (2003) suggested that unwanted relationships cause stress, and stress demands some sort of coping by the individual. He identified the different tactics which people use to deal with unwanted relationships. Primarily, Hess asserted that people try to avoid closeness and self-disclosure with an unwanted person. According to Hess, tactics include avoidance, ignoring and inattention, discounting the hurtful messages, deception, humor, and degrading (i.e., perceiving the other person as less than human).

According to Hess (2003), a behavior that seems universal in unwanted relationships is the effort to distance oneself from the unwanted communication partner. Distance can be created, for example, through making interactions shorter in duration, staying away from the other person as much as possible, or simply ignoring the other. The defensive strategies found by Salmivalli, 
Karhunen, et al. (1996), as well as by Smith and colleagues (2004), share many features with the distancing strategies introduced by Hess, suggesting that the selection of the defensive strategy stems from the characteristics of the relationship between bully and victim. Most challenging for the victims of bullying is to maintain a minimum level of closeness with the unpleasant partner while preserving the relationship with that person (or, at least, maintaining membership in the peer group). Distancing can be a successful strategy at school, but in the contexts of working life, this tactic can make the victim's work even more difficult, since good employees cannot hide from their supervisors and co-workers.

Communication studies should aim at improving our ability to identify mentally violent communication behaviors and processes as well as to identify the communicative strategies that form an effective defense against them. In addition, we should examine production of hurtful communication and the strategies of defense, as well as to the relationship between them. Theoretical and conceptual frameworks from the discipline of communication offer particularly useful resources for explicating such factors.

On the intrapersonal level, communication theories describe, for example, the cognitive processes of individuals in which they set goals for interaction with others and construct communication strategies; produce, perceive and interpret verbal and nonverbal messages, and give meanings and interpretations to messages (i.e., theories of information processing, e.g., the constructivist approach, see Burleson, 1989; Delia, B. O’Keefe, \& D. O’Keefe, 1982). Understanding the intrapersonal dynamics of bullying could also be enhanced through communication research on verbal aggressiveness (Infante \& Wigley, 1986), communication apprehension (McCroskey, 1982), willingness to communicate (McCroskey \& Richmond, 1987), and cognitive complexity (e.g., Burleson \& Caplan, 1998) which direct the cognitive processes, perceptions, and communication behavior of individuals. In addition, significant studies focus on the communication skills and communication competence of individuals (e.g., Cupach \& Spitzberg, 
2002; Greene \& Burleson, 2003; Malcom, 1994; Spitzberg, 1994; S.R. Wilson \& Sabee, 2003). The knowledge concerning communication orientations and communication skills, together with the theories of message production, facilitate understanding why and how some individuals create more complex and sophisticated communication strategies than others to achieve their communication goals (e.g., get social approval from others, gain compliance, affect others' interpersonal relationships, or get a leading position in a group), while others might find it almost impossible to get a single reliable friend or express their opinions in the presence of others.

\section{Antecedents of Bullying at School and in the Workplace}

Previous studies have examined the antecedents of bullying at school and in the workplace on three primary levels: 1) personal characteristics or conditions of an individual, either of a bully or of a victim, 2) dynamic functions of a group, and/or 3) organizational (and cultural) level variables. Since this area of research is large, we have restricted our review to those studies and findings which intersect most connections with communication theory and research. In this section, we will argue that communication research can make a significant contribution in enlarging understanding of associations of bullying with the development of communication relationships between individuals, within groups, and within organizations.

\section{Individual Differences in Communication Behavior}

In the case of school bullying, individual-level factors examined as antecedents of bullying have included physical appearance (e.g., over- or underweight, clumsiness, and physical strength), self-esteem, shyness, insecurity, social withdrawal, anxiety, depression, loneliness, social intelligence, aggressiveness (both reactiveness and proactiveness), the family relationships of an individual (e.g., attachment relationships, family-management practices, and the structural aspects of families), and practices used in upbringing at home. As previous research attests, the most powerful predictors of victimization at the individual level are low self-esteem, shyness or timidity, 
insecurity, sensitivity, and anxiousness on the part of a child (e.g., Olweus, 1993; Salmivalli, 2003). This research emphasizes, however, that features of this kind might not only be causes of bullying, but they might also develop as a consequence of repeated harassment (e.g., Pikas, 1990).

The most typical characteristic of a bullying boy is aggressiveness (e.g., Olweus, 1993), whereas a girl who bullies others is not necessarily aggressive. Instead, she might possess a very high level of social intelligence which she uses against her victim by means of indirect bullying and the manipulation of peer relationships (Kaukiainen, 2003). According to Olweus, a bully usually does not have low self-esteem, neither does he or she express insecurity. Rather, he or she most probably has a strong need for self-assertion and to be at the center of attention (Salmivalli, 1998).

However, previous studies have yielded conflicting results regarding the characteristics of bullies and their victims. On the one hand, bullies have appeared to be aggressive individuals (e.g., Olweus, 1993) with inadequate communication skills, especially in relation to self-control, cooperation, and empathy (Kaukiainen, 2002, 2003). On the other hand, a bully might as easily be a pupil with normally-developed communication skills. He or she might even have exceptionally good communication skills, especially in persuasion, and s/he might be highly perceptive about his/her social environment and the relationships existing among others. He or she might be very competent in establishing friendships, knowing how the other person feels, and making others laugh; in other words, the bully might be very competent in the kinds of communication skills which make him or her a skillful manipulator (see Kaukiainen, 2002, 2003; Weir, 2001).

Kaukiainen (2003) reported a significant relationship between social intelligence and indirect bullying. Social intelligence enables the practice of indirect bullying. Girls tend to be more socially intelligent than boys. As such, they hold the potential to make precise interpretations of the surrounding social reality and influence other people in a tactful way. Usually, social intelligence positively affects relationships, but it can be used in negative ways as well. Future research should 
explore children's skills in argumentation, persuasion, and relational attachment, and the relationships of these skills with bullying.

According to previous studies conducted among school-children, the victims of bullying can be classified into three categories: 1) passive victims, who are typically sensitive, shy, anxious, insecure, careful, and have low self-esteem and a negative communicator image (Olweus, 1993); 2) provocative victims, who are aggressive and irritating to others and might simultaneously be bullies (Olweus, 1993), and 3) ordinary pupils, whom others, for some reason, have selected as a victim (Salmivalli, 1998). Hence, very different kinds of individual-level factors characterize both bullies and their victims.

Corresponding findings have been obtained in working-life contexts. In working life, the individual-level characteristics examined as antecedents of bullying have included differences in the age and gender of the individuals; dissimilarity in thinking, behavior, and values between the individuals; inflexibility of the victim in adapting to the norms and rules of the working community; aggressiveness and inability to communicate in constructive ways; self-esteem of the bully; the tendency of an individual to criticize others' work, and envy and jealousy.

Previous research characterizes the bully or harasser as either an incompetent communicator with a low tolerance of criticism directed against himself/herself or a skilful "player" in interpersonal relationships (Lindroos, 1996; Tasala, 1997). Rainivaara (2004) interviewed individuals who had experienced bullying at their place of work. Respondents described their bullies as dominant, overly self-confident, competitive and verbally aggressive communicators who had deficiencies in their argumentation and listening skills as well as in their ability to take the role of the other and show empathy. At the same time, however, the bullies were adept at protecting their own position by creating a good impression of themselves to others in the work community.

The victim of workplace bullying, in turn, tends to be someone who is rather different, when compared to the others around him. As suggested by Vartia-Väänänen (2003), the "difference” of 
the victim might be a matter of, for example, having the courage to express one's opinions, of unusual diligence, of creativity, or it might be simply a matter of being the only representative of one's own sex, age, or area of expertise. On the other hand, previous studies also suggest that victims can lack sensitivity concerning the implicit rules and norms of the working community, and therefore, they might irritate others (Vartia \& Perkka-Jortikka, 1994).

Studies of bullying rarely focus on the interpersonal relationships between bully and victim. One exception is Einarsen (1999) who divides the origins of bullying into two categories. By dispute-related bullying, Einarsen referred to harassment which develops as a result of an unresolved conflict between individuals. By predatory bullying, on the other hand, Einarsen treated harassment as the means by which the bully tries to achieve some personal advantage, at the victim's expense. Einarsen stated:

Predatory bullying refers to cases where the victim personally has done nothing provocative that may reasonably justify the behaviour of the bully. In such cases the victim is accidentally in a situation where a predator either is demonstrating power or in other ways is trying to exploit an accidental victim into compliance. (p. 22-23)

According to Einarsen, a bullying case typically is triggered by a work-related conflict. Additional research should explore the communication processes where work-related conflict turns into bullying.

In one study, sexually harassed women described two kinds of men. Some men sent sexually harassing verbal and nonverbal messages and seemed to send those messages deliberately in order to increase their power over the target in situations without bystanders present, and other harassers did not seem to have any other kind of model or form of behavior when communicating with women and, therefore, perhaps did not even realize that their behavior was experienced as intrusive (Ryynänen, 2003). The first kind of sexual harassment behavior involves adequate communication skills and goal-orientation, whereas the latter kind of behavior suggests insufficient 
communication skills. In both cases, however, the negative interpretation given to the behavior of the harassers resulted from some kind of violation of communication norms or expectations.

As a general conclusion to the survey of this area of research, the personal characteristics and communication skills examined in previous studies are associated to some extent, at the least, with involvement in bullying, either in the role of bully or victim. However, they do not explain the variance in its entirety. In addition, in some cases, the results are even contradictory. In other words, we have so far identified a number of "types" of individuals who are at risk of becoming involved in bullying, but we do not know for sure that they will. Therefore, we should examine the developmental courses of bullying relationships more closely, in order to determine what kinds of interaction result in the formulation of a bullying relationship. We claim that, rather than being casually formed, the roles of bully and victim are formulated in communication processes taking place between individuals and within groups over a longer period of time. Therefore, we should pursue what actually happens in the processes of interaction that take place between different kinds of persons before and during the development of their relationship into a bullying relationship.

Communication theories that describe the development of interpersonal relationships include uncertainty reduction theory (see Berger, 1987; Berger \& Bradac, 1982), social penetration theory (see Altman \& Taylor, 1973; Taylor \& Altman, 1987), and expectancy violation theory (see Burgoon and Hale, 1988). Each of these theories could facilitate understanding of, in particular, why and how bullying between two individuals starts at the beginning of their acquaintanceship. These theories describe how interpersonal relationships develop in repeated interactions between the partners, how knowledge of the other person deepens by gradually moving on toward more and more intimate issues in discussions, and how partners build trust and mutual understanding of important issues. These theories, together with message-production theories and constructs of communication orientation, could be valuable for expressing how, on some occasions, a close and 
supportive friendship springs up between certain individuals, whereas a bullying relationship develops between others in which only one partner benefits while the other one loses.

Further, the concept of verbal aggression has been applied in communication research to describe violent and hostile communication behavior, either as a traitlike or statelike orientation of an individual (for related review, see Morgan \& Wilson, 2005). Verbally aggressive messages attack an individual's self-concept in order to make the person feel less favorably about himself (Infante \& Wigley, 1986). They can consist of character attacks, competence attacks, insults, maledictions, teasing, ridicule, profanity, threats, and nonverbal indicators (Infante, 1987).

For an individual who constantly expresses aggression with his or her communication behavior, establishing friendships with others than those of the same kind might be difficult because his or her offensive communication style does not tempt others to expose their personal and intimate concerns to him or her. Research suggests that bullies usually hang out with other bullies (Salmivalli, 1998), and they nominate fellow bullies as their friends (Espelage \& Holt, 2001). As a result, instead of learning friendly and supportive forms of communication from other kinds of children and adolescents, they reinforce aggressive forms of communication.

Communication theories and concepts provide potentially useful theoretical and conceptual frameworks for learning how different communication orientations and communication skills relate to interaction processes as well as typical communication patterns for critical situations where the roles of bully and victim are formulated. In future studies, we should examine the individual, relational, and situational factors which increase the probability of a communication relationship turning into a bullying relationship.

\section{Bullying and Harassment as Group Processes}

In this section, we focus on the role of group communication in bullying processes. After providing a review of previous literature in which bullying has been examined as a group process, 
we advance some communication theories as examples of the tools which communication discipline has to offer for the examination of the goals and purposes bullying serves in groups and of the formulation of the roles of bully and victim within the group structure.

Previous research suggests that bullying at school quickly expands into a group process, with several persons involved in different roles. In addition to the bullies and their victims, Olweus (1973) and Salmivalli (1998) as well as O’Connell, Pepler, and Craig (1999) identified various other roles in bullying situations. Some children eagerly join in the bullying when someone initiates it, and they act as "assistants" to the bully. "Reinforcers" provide an audience for the bully, for example, by laughing and giving positive feedback to him/her. Further, a remarkable number of children remain aloof, as "outsiders," from actual bullying situations, but they still allow bullying to go on through their silent approval. Finally, as Salmivalli argued, a few "defenders" linger to support the victim by comforting and taking sides with him/her and by trying to make the others stop bullying.

The roles of individuals in bullying situations have been explained, for example, in terms of group norms and status hierarchies within a group. First, bullying occurs more commonly in school classes where the group norms concerning bullying are rather positive and bullying is seen as acceptable behavior (Salmivalli \& Voeten, 2004). Second, the status of an individual within a group sets limits to the individual's behavior and role in the group. While a pupil with low status (i.e., is not liked, but clearly rejected by peers) most often ends up a victim, a person with high status in the group (i.e., is liked and not rejected by peers) is more freely allowed to choose the role of a defender of the victim, and acting in this role might actually raise his/her status. The status of a bullying boy is usually quite low, whereas bullying girls are either very much liked or very clearly rejected by their peers (Salmivalli, Lagerspetz, et al., 1996).

Other group-level explanations for bullying have been asserted by, for example, Olweus and Pikas. Olweus (1993) suggested that bullying can result from following the behavioral model of an 
admired person, weakened control of one's own aggressive tendencies after seeing that the negative behavior of a bully is rewarded (in terms of "overcoming" the victim) rather than punished (by peers, teachers, or parents, for example), perceptual changes after continual attacks and hurtful comments, resulting in an increased tendency of adolescents to see the victim as a person of no value, and diffusion of individual responsibility when the whole group is involved in bullying. Janis recognized this phenomenon in the theory of Groupthink (see Janis, 1982). The theory suggests that, since responsibility for the decisions made by the group is diffused, a group can end up approving a decision which no single member of the group would have approved on his own. The whole group kicking someone in the school yard or destroying his or her personal property could result from a decision made in this way. We already know that school bullying appears most often in the presence of a larger group. At work, a decision concerning the dramatic cutting of employee resources or increasing his/her work load can be done more easily by an executive group than by an individual employer.

An additional explanation given for school bullying is that the group follows the model of the bully because the members are afraid of becoming victims too, if they resist him/her (Slee, 1994). Further, Pikas (1990) contended that bullying might result from cognitive dissonance caused by the dissimilarity between the victim and others. After this dissonance occurs, members of a group start to "test" the victim in order to classify him/her according to categories that they can recognize. Pikas also argued that members of the group could develop a view of the victim as an enemy. This perception might be completely irrational and independent of the victim's behavior, or it might be caused by a threat from the victim which really has been experienced by the bully.

In work contexts, participant roles in bullying processes have not been empirically examined. However, based on research in school settings, we should investigate the possibilities that, in workplaces where people often form both official and unofficial teams and groups, the harassment of one or several individuals can also take the form of a group phenomenon, with 
individuals participating in different roles (as bullies, victims, assistants, reinforcers, and defenders).

Indeed, several group phenomena have been proposed as explanations of why individuals in workplaces approve the bullying of their workmates or even participate in that bullying. First, the existence of unresolved problems or continuous competition in the working community can result in the employees choosing a victim as a scapegoat whom they can blame for all the problems occurring at the workplace (e.g., Einarsen, 1999; Lindroos, 1996; Thylefors, 1987; Vartia \& Perkka-Jortikka, 1994). As Thylefors detailed, a second explanation for bullying is that a new or somehow different employee becomes rejected by others because of an anticipated (or potential) threat to the working practices or communication relationships of the group. Third, members of a working community may not try to prevent the bullying of their workmates because they fear sharing the victim's fate and be rejected by others.

On the basis of previous research, we already know that, in addition to bully and victim, bystanders play significant roles in bullying processes, and most of these roles serve to support the purposes of the bully instead of the victim. Thus, we can conclude that bullying seems to have a particular purpose in a group, and most of the children and adolescents at school, as well as adults at work, are committed to proceeding toward this purpose. In addition to searching for an explanation of bullying by asking about bully motivations, we must ask what goals and purposes are served in a group by bullying (Kaukiainen, 2002; Salmivalli, 2002) and how members of the group choose their own role in bullying processes. We should also explore the ways in which the roles of bully and victim are produced and reinforced in the interaction processes of the group members. Are these roles developed in the actual bullying situations or based on longer and more extensive processes of group formation?

On the group level, a large amount of communication research has focused on understanding how roles, norms, rules, and status hierarchies develop within groups and how the communication 
characteristics of individuals affect these processes (for a review, see Haslett \& Ruebush, 1999). In addition, existing communication literature describes how groups are developed, how interpersonal relations are established and reinforced in groups, how group cohesion is strengthened or weakened in interaction processes, and how groups are structured and restructured through communication (see, for example, Anderson, Riddle, \& Martin, 1999; Keyton, 1999; Mabry, 1999).

In the following, structuration theory, developed by Giddens (1984) and later applied to small group communication by Poole, provides one example of a useful theoretical framework about the processes of group formation. Structuration theory (see Giddens, 1984; Poole, 1999; Poole, Seibold, \& McPhee, 1996) focuses on the processes by which the formation and reproduction of groups occur and the factors that influence these processes. The theory rests on a distinction between system and structure. A system constitutes a social entity, such as a group, pursuing various practices that give rise to an observable pattern of relations within the group. Structures involve the rules and resources that members use to generate and sustain the group system. Structures provide a kind of "recipe" for acting that comprises a configuration of rules as well as the material and social resources used to bring about the action.

In the theory, structuration serves the central concept representing the nature of structures and the relationship between structure and system. It refers to "the process by which systems are produced and reproduced through members' use of rules and resources" (Poole et al., 1996, p. 117). Thus, on the one hand, members of a group draw on rules and resources (structures) to interact, and, on the other hand, structures exist only by virtue of rules and resources being used in practice.

When the question of accepting a new member of the group arises, the group has to weigh the costs and benefits of accepting the newcomer. The members must evaluate how much pressure accepting a new member will bring for the group to change its structures and rules. Notably, a newcomer might also have significant resources to bring to the group in the form of his/her characteristics, abilities, and knowledge. If a group accepts the new employee, the structures of that 
group will be rebuilt. In a situation of this kind, the group might (often subconsciously) come to the conclusion that the benefits to be gained from accepting the new person are less than the costs that it will entail in the sense of changing the system and structures of the group. Because they perceive the newcomer as a threat to the system and structures of the group, the group members might end up mobbing, or approving the mobbing, of this person.

Why do some groups resort to extreme anti-social actions, such as bullying, while other groups choose to show the boundaries of the group in a friendly way and try to get along with the outsiders, even though they are not willing to risk change to the existing system and structures of the group by accepting them as members? A closer examination of some naturally-occurring groups on the basis of the structuration theory might help to answer this question.

Another advantage of structuration theory is that it considers factors which could have an effect on the processes of bullying. The theory states that several factors influence structuration, for example, by differential distributions of resources among group members and between the group and external actors. Actors with special expertise or privileged positions in a group can control structuration more than novices or individuals with few resources. Potentially, resources which individuals can offer to the group increase or decrease over time, which can affect the restructuration processes.

In the processes of group structuration, communication plays a significant role (Poole, 1999; Poole et al., 1996). By means of communication, the resources of the possible members of a group become identified, structures and rules of the group become negotiated, and group cohesion becomes strengthened. Communication also facilitates the processes of social exclusion. By means of effective persuasion, the members of a group can be convinced that someone deserves to be rejected by others, or should be treated in negative and humiliating ways. For example, in a study conducted by Teräsahjo and Salmivalli (2002), pupils explained why particular individuals were bullied in their school. Participants described victims of bullying as strange or somehow odd and, 
therefore, deserving to be bullied. These kinds of attributions given to bullying reflect the narrative nature of interpersonal persuasion, which has been described in the symbolic convergence theory developed by Bormann (1996). This theory sheds light on the ways in which members of a group integrate themselves into the group by sharing fantasies, which also involves them in sharing common values and ideals, and a common model of reality. The attributions given by children to the bullying of someone seem to represent the fantasies shared in a peer group about victims.

To summarize, bullying can be constructive for those individuals who belong to a particular group but extremely destructive for someone who perceived as an "unworthy" person or even as a threat and who, therefore, instead of being accepted, function as a tool to serve the cohesive purposes of the group. Future studies should especially focus on how bullying relationships between individuals intersect with other interpersonal relationships as well as the structures of the group where the bullying relationship exists.

\section{Organizational and Cultural Level Antecedents of Bullying and Harassment}

In this section, we summarize and compare research which has focused on organizationallevel factors presumed to be antecedents of bullying at school and in workplaces. We also advance some theoretical perspectives to enlarge understanding of bullying as an organizational and cultural communication phenomenon.

As Salmivalli (2003) summarized, organizational-level determinants of school bullying have been pursued in the physical environment of the school (e.g., the size, location, and coziness of the school as well as level of control exercised during breaks), school culture and climate, clarity of the school rules, goal-orientation and general motivation in school-work, and involvement of school personnel in preventing bullying. Class-level investigations of bullying have included, among other things, the management of the class by teachers and the social structure of the class, both of which have been associated with the prevalence of bullying in class (Roland \& Galloway, 2002). 
The norm climate of the school comprises an important factor in bullying at school. A study of bullying-related classroom norms in grades 4, 5 and 6 revealed that, with increasing age, a decrease in anti-bullying norms appears. Defending the victim becomes less approved while joining in bullying becomes more accepted in the upper classes (Salmivalli \& Voeten, 2004).

On the subject of bullying in working life, Leymann (1993) found four factors that could have a significant effect on the occurrence of workplace bullying: 1) deficiencies in the way in which the worker's tasks are defined and organized by management, 2) deficiencies in leadership behavior, 3) a socially-exposed position of the victim, and 4) a low moral standard. In a Finnish study, victims of bullying described their workplace as a highly stressful and competitive environment, full of interpersonal conflicts and lacking a supportive atmosphere, subject to organizational changes, and managed with an authoritarian leadership style (Vartia, 1996). Further, organizational-level antecedents of work harassment have included a high level of role conflicts and the lack of any opportunity for self monitoring of one's work (Einarsen et al., 1994), deficiency in information flow, the lack of mutual discussions concerning tasks and goals, and a low level of influence in matters concerning oneself (Vartia, 1996) as well as job content, social environment, and the lack of control over one's own time combined with high cooperation requirements (Zapf, Knorz, \& Kulla, 1996).

In summary, although organizational-level antecedents of bullying at school and in the workplace appear to include many similar features (e.g., weaknesses in the style of leadership and social structure of a class or organization and failings in the norms or moral standards adopted by members), bullying at work seems to be more clearly associated with task-related antecedents than in school contexts. Thus, when moving from school to working life, the number of organizational risk factors which might lead to bullying increases rather than decreases. Communication practices utilized in the distribution of work, in decision-making, in conflict resolution, and in the giving of 
feedback become critical factors of the organizational culture (see, for example, Hoel \& Salin, 2003; Vartia, 1996).

The meaning of culture in the workplace can also be viewed from a wider perspective. In the communication literature, culture has been examined as a criterion used at workplaces to discriminate against the representatives of certain groups, such as women (e.g., Clair, 1993; Leets \& Giles, 1999; Meares et al., 2004), homosexuals (e.g., Lim, 2003), and ethnic and racial minorities (e.g., Leets \& Giles, 1999; Meares et al., 2004). Discrimination directed against a whole group of people because of their visible difference from the surrounding majority, devalued social identity, or presumed character flaws is sometimes also called stigmatization (see, for example, Miller \& Kaiser, 2001).

Although a large number of organizational and cultural factors impact bullying and harassment at school and in the workplace, we lack a theory which might combine all these factors to explain what organizational and cultural purpose that bullying serves in institutions like schools and workplaces. What kind of societal order or structure does bullying create in these institutions?

Studies have employed muted group theory (Kramarae, 1981) to address the societal purpose of bullying and harassment (see, for example, Clair, 1993, 1994; Hack \& Clair, 1996; LutgenSandvik, 2003; Meares et al., 2004). This theory focuses on lack of voice and resistance to silencing. As summarized by Meares and colleagues, muted group theory is based on four main premises. The first premise is that the members of different groups have varied experiences and, therefore, diverse perceptions of the world. The second premise suggests that each society privileges some groups over others, though individuals at the top of the social hierarchy determine the dominant discourse for that society, reinforcing their own worldview. In this discourse, groups which are not privileged have fewer opportunities to express their experiences and worldviews. The dominant discourse mutes other perspectives. According to the third premise, in order to get their concerns recognized, those belonging to the subordinate groups must use the language and 
communication style of those in the dominant group. The fourth premise states, however, that resistance and change are possible.

On the basis of this theory, Clair (1993) analysed women's interviews concerning their experiences of sexual harassment at work. Paying attention to the ways in which these women told their stories, she found that the framing of sexual harassment stories portrayed the harassment as a hegemonic device which served to maintain the interests of the dominant group. Clair identified six types of framing device: accepting dominant interests, simple misunderstanding, reification, trivialization, denotative hesitancy, and public/private expression - public/private domain. While we advise interested readers to examine the work of Clair more specifically in order to familiarize themselves with all six types of framing device, we limit our review here to consideration of those techniques which might explain the framing of sexual harassment as well as the framing techniques of bullying at school and in the workplace.

As described by Clair (1993), the simple misunderstanding framing device can be noted in the frequent explanation that women may have misconstrued flirting as sexual harassment. If we apply this framing to the work-contexts more generally, it might be identified in a case where a superior who has been accused of harassment explains that the steps taken to reorganize the work of an employee were necessary for the organization, but the employee simply took it too personally. At school, pupils can often be heard to say that "We were just teasing him/her, but he/she was offended, because he/she does not have any sense of humor." For the victimized individual, however, the experience remained serious and damaging. On the same lines as the simple misunderstanding framing device, trivialization may take place, invalidating the abusive situation and denying the experience of the target by turning the event into a joke. Students may assert that "We were teasing him/her just for fun; it was nothing else but play," or "I was not referring to his/her sexual orientation with my comment. Can’t he/she take a joke?” 
Denotative hesitancy refers to the constraints that the subjugated group feels in expressing itself because the existing vocabulary of the institution defines the institution's reality only from the perspective of the dominant group. Therefore, the members of the subjugated group can be without the means of expression necessary to convey their own narrative or define their own experience. Clair (1993) argued that, when new terms (e.g., sexual harassment) are introduced into a language system, their definitions must be contested before language users reach consensus about their denotative meaning. Hence, as long as bullying and harassment as concepts and phenomena are not generally identified (and their existence at school and in the workplace is, therefore, not admitted and openly discussed), the subjugated groups remain confused and without the means to recognize the nature of their experience. This circumstance can be observed in the accounts of previous victims, when they explain in later years that, during their schooldays, they never understood that what they experienced was school bullying.

As we pointed out earlier in the chapter, the imbalance of power between the parties is one of the main characteristics of bullying as identified by researchers in various definitions. LutgenSandvik (2003) applied muted group theory in explaining bully's and victim's inequality of access to power in the superior-subordinate-relationship. She argued that individuals who have access to structural (hierarchical) power dominate organizational language in the workplace. As a result, the dominant language likely reflects productivity or other organizational goals and might not reveal subordinate employees' workplace experiences. Applying muted group theory, she proposed an extension of Leymann's (1990) linear model of workplace mobbing to describe the developmental phases of employee emotional abuse. Furthermore, Meares and colleagues (2004) examined employee mistreatment through the perspectives of employees with different cultural backgrounds in order to understand how some voices are muted and others privileged in an organization.

If we regard victims of bullying and harassment as members of the muted group, new questions arise. What features characterize the members of the muted group and members of the 
dominant group, at school and in workplaces of different kinds? What kinds of individual characteristics, skills, and behavioral features are used to "justify" the bullying of one person and privilege another to bully, and how are these justifications negotiated in the interaction processes of the individuals involved? Answers to these questions might be found by investigating the attributions which are given to bullying others or to being bullied. Previous studies suggest that children at school, both victims and others, tend to find justification for bullying in the characteristics and behavior of the victim (Hoover et al., 1992; Teräsahjo \& Salmivalli, 2002), rather than in those of the bully.

Bullying might also be regarded as a way of teaching an individual to follow the norms and rules of the organization, as could be presumed to occur in the cases of bully-victims where pupils start to bully an individual who acts aggressively towards others. However, bullying others seems to be acceptable behavior in the case of some students, while, for others, it is not. Are there certain characteristics of individuals which privilege them to bully others, or are these individuals just employing more acceptable forms of bullying?

Muted group theory constitutes one example of the communication perspectives which can be applied to bullying. Previous studies of organizational communication (see, for example, Hoel \& Salin, 2003; House, Hanges, Javidan, Dorfman, \& Gupta, 2004; Taylor, Flanagan, Cheney, \& Seibold, 2001; Vartia, 1996), conflict management (see, for example, De Dreu \& Van de Vliert, 1997; Hample, 1999; Keashly \& Nowell, 2003; Kellet \& Dalton, 2001), leadership (see, for example, Connaughton \& Daly, 2005), and feedback (see, for example, Kluger \& DeNisi, 1996; Lizzio, Wilson, Gilchrist, \& Gallois, 2003) shed light on the communicative factors which direct the communication climate of the workplace, the development of conflicts, organizing of tasks, and the developmental courses of bullying processes. This research could help in understanding the organizational-level risk factors in the processes of bullying as well as in finding tools for directing organizations in a more supportive and less violent direction. 


\section{Managing the Costs of Bullying with Social Support}

For the victim, bullying or harassment comprises a traumatic experience which markedly reduces the quality of life. At school, the anxiety and fear experienced by bullied children often lead to serious motivation and learning difficulties, negative attitudes toward schooling, and to impaired academic achievement (Mottet \& Thweatt, 1997). According to the literature, bullying can lead to lowered self-esteem and feelings of loneliness, anxiety, and depression (Boulton \& Smith, 1994; Callaghan \& Joseph, 1995; Hodges \& Perry, 1996; Kaltiala-Heino, M. Rimpelä, Rantanen, \& A. Rimpelä, 2000), and over time, to psychosomatic symptoms of stress, such as increased somatic complaints and more illnesses (Boulton \& Smith, 1994; Kaltiala-Heino et al., 2000; Rigby, 1998) as well as mental health problems such as eating disorders (Kaltiala-Heino et al., 2000). Surprisingly, recent studies have demonstrated that victims and bullies both suffer from depressive symptoms (Kaltiala-Heino, M. Rimpelä, Rantanen, \& A. Rimpelä, 1998; Roland, 2002a), and they experience suicidal thoughts (Kaltiala-Heino et al., 1998; Roland, 2002b) and psychosomatic symptoms (Vikat, 1998) more often than pupils who are not involved in bullying at school.

Similarly, hostile behavior in the workplace significantly affects victims on individual and organizational levels. Keashly and Jagatic (2003) detailed the effects of workplace bullying. They divided the effects of workplace bullying into direct and indirect effects. Direct effects encompass negative mood (anger, resentment, anxiety) as well as fear of violence and cognitive distraction (depressed mood, fear, loss of concentration). Indirect effects decrease the psychological well-being of the target, such as lowered self-esteem and life satisfaction, problem drinking, depression, overall emotional health, and symptoms of post-traumatic stress-disorder, PTSD (see also Björkqvist et al., 1994; Leymann, 1992; C.B. Wilson, 1991). Indirect effects also include poor psychosomatic functions of the target (physically weak health) and reduced organizational functioning, at least partially signified through decreased job satisfaction, greater turnover of workers, increased 
absenteeism, decreased productivity and greater intention to leave. Further consequences of bullying at work span insomnia, various nervous symptoms, melancholy, apathy, and socio-phobia (Björkqvist et al., 1994) as well as social isolation, stigmatizing, social maladjustment, psychosomatic illnesses, compulsions, helplessness, and despair (Leymann, 1990). Sexual harassment leads especially to a decreased level of self-esteem, the feeling of not being professionally appreciated, fear of the opposite sex, feelings of shame, and suspicion of employers (Alemay et al., 1999; Timmerman \& Bajema, 1999).

To conclude, in addition to the suffering during actual threatening communication situations, bullying and harassment can have long-lasting effects on an individual's overall psychosocial well-being, personal relationships, and career development. Furthermore, bullying is not only a personal problem for the individual victim. It can have serious consequences for the bully as well as for families, friends, and relatives of both the victim and the bully and the whole community where the problem exists.

Social support has a central role in an individual's coping processes. A growing body of research demonstrates that supportive interpersonal relationships buffer the negative consequences of peer rejection and victimization at school (e.g., Hodges, Boivin, Vitaro, \& Bukowski, 1999; Parker \& Asher, 1993). According to Einarsen (2000), victims with high social support at work or off work probably feel less vulnerable when faced with aggression because social support can reduce the emotional and physiological activation of the victim, hence reducing the health effects of long-term bullying.

Previous studies suggest, however, that the victims of bullying seldom receive support from their peers in a concrete and perceivable way. In cases of school bullying, the number of individuals who defend victims is small (Salmivalli, 1998; Salmivalli, Lagerspetz, et al., 1996). Similar findings characterize cases of workplace harassment. Lutgen-Sandvik (2003), for example, described the final stages of the communicative cycle of employee emotional abuse. During these 
final stages, fear and intimidation silence both the targets and the other employees. Most coworkers do not speak up in the face of collegial abuse, so targets are silenced and separated from support. In addition to fearing reprisal, providing support for a bullied coworker drains energy from peers, and they can become emotionally exhausted and withdraw support from a colleague who seems to be too demanding or takes too much of their energy. Even the family members of the victim can become emotionally exhausted and withdraw their support.

In communication studies, social support and supportive communication have been investigated in several other contexts: in health-care, family, and close relationships (see, for example, Burleson, Albrecht, \& Sarason, 1994; Gardner \& Cutrona, 2004), but not in the context of bullying and harassment. The communication processes and interpersonal relationships in which social support is given to the individuals involved in bullying should be examined both among children and adults. Important questions remain: Who are the best providers of support in bullying cases, and what kind of social support and supportive communication is expected and needed by the victims from different sources (e.g., parents, siblings, mates, friends, teachers and other school personnel, superiors, and workmates)? Is the mate at home expected to provide a different kind of support from that required from the superior at work, and is the support needed from parents different from the support required from teachers at school? Further, do individuals differ in their need of social support in cases of bullying, and how does support affect different kinds of victim? What kinds of differences exist in the availability of support between victims or victim groups? Finally, researchers should pursue the kinds of support that bullies need and receive; how does a bully communicate his or her need to others, and what are the effects of support received by the bully?

\section{Conclusion}


Although bullying has been studied both in school and working-life contexts, research combining these two areas is rare. We already know that, although the extent of bullying can be reduced by means of effective interventions by highly-committed personnel involved at school (see, for example, Olweus, 2003; Roland, Bjørnsen, \& Mandt, 2003; Salmivalli, 2003), the roles of bullies and victims seem to be quite permanent at school. We also know that, the older children get, the more likely they are to accept bullying behaviors directed toward others (Espelage \& Holt, 2001; Salmivalli, 2003). Similarly, at the workplace, once harassment begins, it tends to continue until the victim leaves his or her work.

Research suggests that the forms of both bullying and self-defense become more skilled and sophisticated as the participants grow older. Simultaneously, while the forms of indirect bullying increase, the meanings and interpretations given to communication behavior become more significant, and outsiders face increasing difficulty in recognizing bullying when it occurs. As a result, the examination of bullying grows even more challenging, since the subjective aspects of the phenomenon increasingly predominate.

Verbally and nonverbally hurtful messages, and the meanings given to them, as well as their effects in bullying situations have not received much attention in communication research. Further, research focusing on the strategies of defense as communication acts in actual bullying situations is rare in studies concerning workplace bullying, while in the studies of school bullying, less attention has been paid to the long-term coping strategies of victims. Communication studies should aim to improve our ability to identify mentally violent communication behaviors and processes as well as to identify the communicative strategies (both immediate and long-term) that form an effective defense against them.

However, labeling an individual's behaviors as bullying or harassment could be difficult because the meanings and interpretations given to communication behavior vary from one person to another. The same phrase, gesture, laughter, or touch might be interpreted quite differently by 
various recipients who will assess that phrase, etc. in light of the interpersonal relationship that they have with the sender and their history of interactions with him/her. Therefore, the same kind of message can be received as a spontaneous, harmless joke by one person and as a repeated, painful insult by another. Similarly, the ability of an individual to defend himself might be estimated from the verbal and nonverbal messages he sends, and they must also be interpreted in the light of the previous knowledge gained of the sender and the relationship that he or she has with the bully. In future research, more attention should be paid to the factors directing the production of hurtful communication and the strategies of defense as well as to the relationship between them. Here, communication theories and concepts provide useful tools for researchers.

In the beginning of the chapter, we examined definitions given to bullying and related concepts. We suggested that, in addition to the tradition of previous research which approached bullying as the behavior of an individual directed to another individual or individuals, we should pay more attention to the bullying relationship as a communication relationship taking place between individuals within groups and organizations. This perspective means making the interaction and relationships of individuals the centre of attention and moving the characteristics of the individuals involved into the background (without forgetting them). The benefits of this kind of approach could be found in an increased understanding of the interpersonal, organizational, and group processes leading to bullying. On the basis of this approach, several questions call for the contribution of communication scholars.

Future research should focus, first, on the developmental courses of bullying relationships and on the variation to be found in them, both in the contexts of school and working life. By means of this research, we should learn to identify bullying relationships and communication relationships which are at risk of becoming such as well as individuals who are at risk of falling into bullying relationships. 
Second, the different participant roles which have been specified in studies of school bullying should also be studied in the contexts of working life. We have presumed that these roles are formed in the communication processes of a group during a longer period of time, and their existence serves mainly constructive purposes in the group (e.g, the strengthening of group cohesion as well as group structuring and restructuring), although, simultaneously, it may become extremely destructive for the "outsider" of the group who has been chosen as victim. The development of these roles in the interaction of the group needs further examination.

Third, research into school bullying, in turn, would benefit from applying theories of organizational and cultural communication, such as muted group theory. This kind of research could reveal the typically muted groups among children and detail how their voices become muted. Is the subjugation of these children groups based on racial, ethnic, or gender-related discrimination, the physical appearance of these children (e.g., obesity, physical unattractiveness, or a visible disability), or their communication skills and orientations, such as shyness or reticence, low levels of assertiveness, or insufficient relational skills? If certain groups of children are more vulnerable than others to becoming subjugated, we should investigate how the rules governing subjugation and the assigning of privilege are transferred from adults to children. Do adults at home and at school participate in the subjugating process? Are the same individuals and groups at risk of becoming victimized or becoming bullies, first at school and then later in the workplace?

In searching for an understanding of bullying among children and adults, the benefits of the core theories of information processing and interpersonal and group communication have been ignored so far. Communication theories can help in understanding bullying and harassment, and their advantages can be easily recognized. However, empirical research applying these theories to explain bullying and harassment processes is almost entirely lacking.

In what ways can knowledge concerning bullying be used in order to get a better understanding of the socio-communicative nature of humans? What can be done to make a change 
in existing conditions and in the behavior of individuals? Increasing understanding of the communication processes involved in school bullying and workplace harassment will certainly enhance our understanding of human communication behavior in other kinds of contexts and relationships where mentally and/or physically violent behavior appears. This behavior might be realized as verbal and physical abuse in domestic surroundings, coercion and subjection in romantic relationships, bullying and harassment in the out-of-school activities of adolescents, ethnic and racial harassment and rejection among individuals or groups representing different cultures or subcultures, or as hostile behavior in the conflicts between nations. Crawford (1999), for example, broadened the term bullying to include incidents on an international level, as phenomena occurring between nations. The accumulation of armaments or the testing of nuclear weapons can be regarded as nations demonstrating their power to attack each other. In addition, the methods of prevention, intervention, and the provision of support in one context of bullying are often obviously transferable to other contexts of the same kind. The study of bullying in human relationships is a great challenge for communication theory and research. 


\section{References}

Adams, A. (1992). Bullying at work: How to confront and overcome it? London: Virago Press.

Alberts, J. K., Lutgen-Sandvik, P., \& Tracy, S. J. (2005, May). Workplace bullying: A case of escalated incivility. Paper presented at the annual meeting of the International Communication Association, New York.

Alemay, M. -C., Boyer, J., Cattaneo, N., Paparriga-Costavara, C., Bergamaschi, M., \& Campino, M. M. (1999). Sexual harassment at work in five Southern European Countries. In Sexual harassment at the workplace in the European Union (pp. 155-233). Luxembourg, Luxembourg: Office for Official Publications of the European Communities.

Altman, I., \& Taylor, D. (1973). Social penetration: The development of interpersonal relationships. New York: Holt.

Anderson, C. M., Riddle, B. L., \& Martin, M. M. (1999). Socialization processes in groups. In L. R. Frey, D. S. Gouran, \& M. S. Poole (Eds.), The handbook of group communication theory and research (pp. 139-166). Thousand Oaks, CA: Sage.

Ashforth, B. (1994). Petty tyranny in organizations. Human Relations, 47, 755-778.

Baron, R. A., \& Neuman, J. H. (1996). Workplace violence and workplace aggression: Evidence on their relative frequency and potential causes. Aggressive Behavior, 22, 161-173.

Batsche, G. M., \& Knoff, H. M. (1994). Bullies and their victims: Understanding a pervasive problem in the schools. School Psychology Review, 23, 165-175.

Berger, C. R. (1987). Communicating under uncertainty. In M. Roloff \& G. Miller (Eds.), Interpersonal processes: New directions in communication research (pp. 39-62). Newbury Park, CA: Sage.

Berger, C. R., \& Bradac, J. J. (1982). Language and social knowledge: Uncertainty in interpersonal relations. London: Edward Arnold. 
Björkqvist, K., Ekman, K., \& Lagerspetz, K. (1982). Bullies and victims: Their ego picture, ideal ego picture and normative ego picture. Scandinavian Journal of Psychology, 23, 307-313.

Björkqvist, K., Lagerspetz, K., \& Kaukiainen, A. (1992). Do girls manipulate and boys fight? Developmental trends regarding direct and indirect aggression. Aggressive Behavior, 18, $117-127$.

Björkqvist, K., Österman, K., \& Hjelt-Bäck, M. (1994). Aggression among university employees. Aggressive Behavior, 20, 27-33.

Bormann, E. G. (1996). Symbolic convergence theory and communication in group decision making. In R. Y. Hirokawa \& M. S. Poole (Eds.), Communication and group decision making (2nd ed., pp. 81-113). London: Sage.

Boulton, M., \& Smith, P. K. (1994). Bully/victim problems in middle-school children: Stability, self-perceived competence, peer perceptions and peer acceptance. British Journal of Developmental Psychology, 12, 315-329.

Brodsky, C. M. (1976). The harassed worker. Toronto, Canada: Lexington Books, DC Health.

Brown, P., \& Levinson, S. (1987). Politeness: Some universals in language usage ( $2^{\text {nd }}$ ed.). Cambridge, England: Cambridge University Press.

Burgoon, J. K., \& Hale, J. (1988). Nonverbal expectancy violations: Model elaboration and application to immediacy behaviors. Communication Monographs, 55, 58-79.

Burleson, B. R. (1989). The constructivist approach to person-centered communication: Analysis of a research exemplar. In B. Dervin, L. Grossberg, B. J. O’Keefe, \& E. Wartella (Eds.), Rethinking communication (Vol. 2, pp. 29-36). Newbury Park, CA: Sage.

Burleson, B. R., Albrecht, T. L., \& Sarason, I. G. (Eds.). (1994). Communication of social support: Messages, interactions, relationships, and community. Thousand Oaks, CA: Sage. 
Burleson, B., \& Caplan, S. (1998). Cognitive complexity. In J. McCroskey, J. Daly, \& M. Martin (Eds.), Communication and personality: Trait perspectives (pp. 233-286). Cresskill, NJ: Hampton Press.

Callaghan, S., \& Joseph, S. (1995). Self-concept and peer victimization among schoolchildren. Personality and Individual Differences, 18, 161-163.

Clair, R. P. (1993). The use of framing devices to sequester organizational narratives: Hegemony and harassment. Communication Monographs, 60, 113-136.

Clair, R. P. (1994). Resistance and oppression as a self-contained opposite: An organizational communication analysis of one man's story of sexual harassment. Western Journal of Communication, 58, 235-262.

Collins, E. F., \& Bahar, E. (2000). To know shame: Malu and its uses in Malay societies. Crossroads, 14, 35-69.

Connaughton, S. L., \& Daly, J. A. (2005). Leadership in the new millennium: Communication beyond temporal, spatial, and geographical boundaries. In P. J. Kalbfleisch (Ed.), Communication yearbook 29 (pp. 203-218). Mahwah, NJ: Erlbaum.

Cooper, C., Faragher, B, \& Hoel, H. (2004). Bullying is detrimental to health, but all bullying behaviours are not necessarily equally damaging. British Journal of Guidance and Counselling, 32, 367-387.

Crawford, N. (1999). Conundrums and confusion in organisations: The etymology of the word “bully.” International Journal of Manpower, 20, 86-93.

Crick, N., \& Dodge, K. (1994). A review and reformulation of social information-processing mechanism in children's social adjustment. Psychological Bulletin, 115, 74-101.

Cupach, W. R., \& Metts, S. (1994). Facework. Thousands Oaks, CA: Sage. 
Cupach, W. R., \& Spitzberg, B. H. (2002). Interpersonal skills. In M. L. Knapp \& J. A. Daly (Eds.), Handbook of interpersonal communication (3rd ed., pp. 564-612). Thousand Oaks, CA: Sage.

Davidson, M. J., \& Cooper, C. L. (1992). Shattering the glass ceiling. London: Paul Chapman.

De Dreu, C., \& Van de Vliert, E. (Eds.). (1997). Using conflict in organizations. London: Sage.

Delia, J., O’Keefe, B., \& O’Keefe, D. (1982). The constructivist approach to communication. In F. E. X. Dance (Ed.), Human communication theory (pp. 147-191). New York: Harper and Row.

Einarsen, S. (1999). The nature and causes of bullying at work. International Journal of Manpower, 20, 16-27.

Einarsen, S. (2000). Harassment and bullying at work: A review of the Scandinavian approach. Aggression and Violent Behavior, 5, 379-401.

Einarsen, S., Hoel, H., Zapf, D., \& Cooper, C. (Eds.). (2003). Bullying and emotional abuse in the workplace: International perspectives in research and practice. London: Taylor \& Francis.

Einarsen, S., \& Raknes, B. I. (1997). Harassment in the workplace and the victimization of men. Violence and Victims, 12, 247-263.

Einarsen, S., Raknes, B. I., \& Matthiesen, S. B. (1993). Seksuell trakassering [Sexual harassment]. Bergen, Norway: Sigma Forlag.

Einarsen, S., Raknes, B. I., \& Matthiesen, S. B. (1994). Bullying and harassment at work and their relationships to work environment quality: An exploratory study. European Work and Organizational Psychologist, 4, 381-401.

Einarsen, S., Raknes, B. I., Matthiesen, S. B., \& Hellesöy, O. H. (1996). Bullying at work and its relationships with health complaints. Moderating effects of social support and personality. Nordisk Psykologi, 48, 116-137. 
Einarsen, S., \& Skogstad, A. (1996). Bullying at work: Epidemiological findings in public and private organizations. European Journal of Work and Organizational Psychology, 5, 185201.

Einarsen, S., \& Sørum, D. (1996). Arbeidskamerat eller sex-objekt? En krysskulturell studie av seksuell trakassering [Coworker or sex-object? A cross-cultural study on sexual harassment at work]. Nordisk Sexologi, 14, 17-33.

Espelage, D. L., \& Holt, M. K. (2001). Bullying and victimization during early adolescence: Peer influences and psychosocial correlates. In R. A. Geffner, M. Loring, \& C. Young (Eds.), Bullying behavior: Current issues, research, and interventions (pp. 123-142). New York: Haworth Press.

Fitzgerald, L. F., Gelfand, M. J., \& Drasgow, F. (1995). Measuring sexual harassment: Theoretical and psychometric advances. Basic and Applied Social Psychology, 17, 425-445.

Fitzgerald, L. F., \& Shullman, S. L. (1993). Sexual harassment: A research analysis and agenda for the 1990s. Journal of Vocational Behavior, 42, 5-27.

Folkman, S., \& Lazarus, R. S. (1984). Stress, appraisal, and coping. New York: Springer.

Gardner, K. A., \& Cutrona, C. E. (2004). Social support communication in families. In A. L. Vangelisti (Ed.), Handbook of family communication (pp. 495-512). Mahwah, NJ: Erlbaum.

Giddens, A. (1984). The constitution of society: Outline of the theory of structuration. Cambridge, England: Polity Press.

Goffman, E. (1967). Interaction ritual: Essays on face-to-face behavior. New York: Pantheon Books.

Greene, J. O., \& Burleson, B. R. (Eds.). (2003). Handbook of communication and social interaction skills. Mahwah, NJ: Erlbaum. 
Hack, T. J., \& Clair, R. P. (1996). Sexual harassment: Raising consciousness and sharing solutions. In E. B. Ray (Ed.), Case studies in communication and disenfranchisement: Applications to social health issues (pp. 151-162). Mahwah, NJ: Erlbaum.

Hample, D. (1999). The life space of personalized conflicts. In M. E. Roloff (Ed.), Communication yearbook 22 (pp. 171-208). Thousand Oaks, CA: Sage.

Harris, J. R. (1995). Where is the child's environment? A group socialization theory of development. Psychological Review, 102, 458-489.

Haslett, B. B., \& Ruebush, J. (1999). What differences do individual differences in groups make? The effects of individuals, culture, and group composition. In L. R. Frey, D. S. Gouran, \& M. S. Poole (Eds.), The handbook of group communication theory and research (pp. 115138). Thousand Oaks, CA: Sage.

Hazler, R. J.,_\& Miller, D. L. (2001). Adult recognition of school bullying situations. Educational Research, 43, 133-146.

Heiskanen, M., \& Piispa, M. (1998). Usko, toivo, hakkaus. Kyselytutkimus miesten naisille tekemästä väkivallasta [Faith, hope, hitting. A survey of the violence directed towards women by men] (Justice, No. 12). Helsinki, Finland: Statistics Finland: Council for Equality (Edita).

Hess, J. A. (2003). Maintaining undesired relationships. In D. J. Canary \& M. Dainton (Eds.), Maintaining relationships through communication: Relational, contextual, and cultural variations (pp. 103-126). Mahwah, NJ: Erlbaum.

Ho, D. Y. (1976). On the concept of face. American Journal of Sociology, 81, 867-884.

Hodges, E. V. E., Boivin, M., Vitaro, F., \& Bukowski, W. M. (1999). The power of friendship: Protection against an escalating cycle of peer victimization. Developmental Psychology, 35, 94-101. 
Hodges, E. V. E., \& Perry, D.G. (1996). Victims of peer abuse: An overview. Journal of Emotional and Behavioral Problems, 5, 23-28.

Hoel, H., \& Cooper, C. L. (2001). Origins of bullying. Theoretical frameworks for explaining workplace bullying. In N. Tehrani (Ed.), Building a culture of respect: Managing bullying at work (pp. 3-19). London: Taylor \& Francis.

Hoel, H., Cooper, C. L., \& Faragher, B. (2001). The experience of bullying in Great Britain: The impact of organizational status. European Journal of Work and Organizational Psychology, $10,443-465$.

Hoel, H., \& Salin, D. (2003). Organizational antecedents of workplace bullying. In S. Einarsen, H. Hoel, D. Zapf, \& C. Cooper (Eds.), Bullying and emotional abuse in the workplace: International perspectives in research and practice (pp. 203-218). London: Taylor \& Francis.

Hogh, A., \& Dofradottir, A. (2001). Coping with bullying in the workplace. European Journal of Work and Organizational Psychology, 10, 485-495.

Hoover, J. H., Oliver, R., \& Hazler, R. J. (1992). Bullying: Perceptions of adolescent victims in the midwestern USA. School Psychology International, 13, 5-16.

House, R. J., Hanges, P. J., Javidan, M., Dorfman, P. W., \& Gupta, V. (Eds.). (2004). Culture, leadership, and organizations: The GLOBE study of 62 societies. Thousand Oaks, CA: Sage.

Hu, H. C. (1944). The Chinese concepts of “face.” American Anthropologist, 46, 45-64.

Infante, D. A. (1987). Aggressiveness. In J. C. McCroskey \& J. A. Daly (Eds.), Personality and interpersonal communication (pp. 157-192). Newbury Park, CA: Sage.

Infante, D. A., \& Wigley, C. J. (1986). Verbal aggressiveness: An interpersonal model and measure. Communication Monographs, 53, 61-69. 
Janis, I. L. (1982). Groupthink: Psychological studies of policy decisions and fiascos (2nd ed.).

Boston: Houghton Mifflin.

Kaltiala-Heino, RK., Rimpelä, M., Rantanen, P., \& Rimpelä, A. (1998). Koulukiusaaminen, masentuneisuus ja itsetuhoajatukset [School bullying, depression, and suicidal thoughts]. Suomen Lääkärilehti, 53(26), 2799-2808.

Kaltiala-Heino, RK., Rimpelä, M., Rantanen, P., \& Rimpelä, A. (2000). Bullying at school - an indicator of adolescents at risk for mental disorders. Journal of Adolescence, 23, 661-674.

Kannas, L., \& Brunell, V. (Eds.). (2000). Subjektiv hälsa, hälsovanor och skoltrivsel. Jämförelse mellan svensk- och finskspråkiga elever 1994-1998 [Subjective health, health behaviour and school satisfaction. A comparative study of Finnish- and Swedish-speaking schoolchildren in Finland in 1994-1998] (Terveystieteiden laitoksen julkaisusarja, No. 10) [Publication reports of the Department of Health Sciences, No. 10]. Jyväskylä, Finland: University of Jyväskylä, Department of health sciences.

Kannas, L., Välimaa, R., Liinamo, A., \& Tynjälä, J. (1995). Oppilaiden kokemuksia kouluviihtyvyydestä ja kuormittuneisuudesta sekä koulukiusaamisesta Euroopassa ja Kanadassa [School children's experiences of school satisfaction and stress and bullying at school in Europe and Canada]. In L. Kannas (Ed.), Koululaisten kokema terveys, hyvinvointi ja kouluviihtyvyys. WHO-koululaistutkimus [Perceived health, well-being and school satisfaction among school children. The HBSC-study] (pp. 131-149). Helsinki, Finland: National Board of Education.

Kaukiainen, A. (2002). Onko aggressio ja kiusaaminen aina sosiaalisen kompetenssin puutetta? [Do aggression and bullying always indicate a lack of social competence?] Psykologia, 37, 115123. 
Kaukiainen, A. (2003). Social intelligence as a prerequisite of indirect aggression: Some manifestations and concomitants of covert forms of aggression (Annales Universitatis Turkuensis, Ser. B-257). Turku, Finland: University of Turku.

Keashly, L. (1998). Emotional abuse in the workplace: Conceptual and empirical issues. Journal of Emotional Abuse, 1, 85-117.

Keashly, L., \& Jagatic, K. (2003). By any other name: American perspectives on workplace bullying. In S. Einarsen, H. Hoel, D. Zapf, \& C. L. Cooper (Eds.), Bullying and emotional abuse in the workplace: International perspectives in research and practice (pp. 31-61). London: Taylor \& Francis.

Keashly, L., \& Nowell, B. L. (2003). Conflict, conflict resolution and bullying. In S. Einarsen, H. Hoel, D. Zapf, \& C. Cooper (Eds.), Bullying and emotional abuse in the workplace: International perspectives in research and practice (pp. 339-358). London: Taylor \& Francis.

Keashly, L., Trott, V., \& MacLean, L. M. (1994). Abusive behavior in the workplace: A preliminary investigation. Violence and Victims, 9, 125-141.

Kellet, P. M., \& Dalton, D. G. (2001). Managing conflict in a negotiated world: A narrative approach to achieving dialogue and change. Thousand Oaks, CA: Sage.

Keyton, J. (1999). Relational communication in groups. In L. R. Frey, D. S. Gouran, \& M. S. Poole (Eds.), The handbook of group communication theory and research (pp. 192-224). Thousand Oaks, CA: Sage.

Kinney, T. A. (1994). An inductively derived typology of verbal aggression and its association to distress. Human Communication Research, 21, 183-222.

Kinney, T. A. (2003). Themes and perceptions of written sexually harassing messages and their link to distress. Journal of Language and Social Psychology, 22, 8-28. 
Kluger, A. N., \& DeNisi, A. (1996). The effects of feedback interventions on performance: A historical review, a meta-analysis, and a preliminary feedback intervention theory. Psychological Bulletin, 119, 254-284.

Kramarae, C. (1981). Women and men speaking. Rowley, MA: Newbury House.

Kreps, G. L. (Ed.). (1993). Sexual harassment: Communication implications. Cresskill, NJ: Hampton Press.

Lagerspetz, K. (1998). Naisten aggressio [Female aggression]. Helsinki, Finland: Tammi.

Lagerspetz, K., Björkqvist, K., Berts, M., \& King, E. (1982). Group aggression among school children in three schools. Scandinavian Journal of Psychology, 23, 45-52.

Leets, L., \& Giles, H. (1999). Harmful speech in intergroup encounters: An organizational framework for communication research. In M. E. Roloff (Ed.), Communication yearbook 22 (pp. 91-138). Thousand Oaks, CA: Sage.

Lehto, A. -M., \& Sutela, H. (2004). Uhkia ja mahdollisuuksia. Työolotutkimusten tuloksia 19772003 [Threats and possibilities. Results from the Finnish working conditions research made in 1977-2003]. Helsinki, Finland: Statistics Finland (Edita).

Leymann, H. (1986). Vuxenmobbning. Om psykiskt våld $i$ arbetslivet [Adultmobbing. About mental violence in working life]. Lund, Sweden: Studentlitteratur.

Leymann, H. (1990). Mobbing and psychological terror at workplaces. Violence and Victims, 5, $119-126$.

Leymann, H. (1992). Från mobbning till utslagning i arbetslivet [From mobbing to expulsion in work life]. Stockholm, Sweden: Publica.

Leymann, H. (1993). Mobbing - Psychoterror am Arbeitsplatz und wie man sich dagegen wehren kann [Bullying - Psycho-terror at work and how one might protect oneself]. Rowolt, Germany: Reinbeck. 
Leymann, H. (1996). The content and the development of mobbing at work. European Journal of Work and Organizational Psychology, 5, 165-184.

Lim, V. K. G. (2003). Managing HIV at the workplace: An empirical study of HIV and HR managers in Singapore. Journal of Occupational Health Psychology, 8, 235-246.

Lindroos, R. (1996). Kiusaamisen kurjuus yhteisöissä ja työyhteisöissä [The misery of harassment in society and at work] (Labour Policy Studies No. 164). Helsinki, Finland: Ministry of Labour.

Lizzio, A., Wilson, K. L., Gilchrist, J., \& Gallois, C. (2003). The role of gender in the construction and evaluation of feedback effectiveness. Management Communication Quarterly, 16, 341379.

Lutgen-Sandvik, P. (2003). The communicative cycle of employee emotional abuse: Generation and regeneration of workplace mistreatment. Management Communication Quarterly, 16, 471501.

Mabry, E. A. (1999). The systems metaphor in group communication. In L. R. Frey, D. S. Gouran, \& M. S. Poole (Eds.), The handbook of group communication theory and research (pp. 7191). Thousand Oaks, CA: Sage.

Malcom, R. P. (1994). Communicative competence and interpersonal control. In M. L. Knapp \& G. R. Miller (Eds.), Handbook of interpersonal communication (pp. 589-618). Thousand Oaks, CA: Sage.

McCroskey, J. C. (1982). An introduction to rhetorical communication (4th ed). Englewood Cliffs, NJ: Prentice Hall.

McCroskey, J. C., \& Richmond, V. (1987). Willingness to communicate. In J. C. McCroskey \& J. A. Daly (Eds.), Personality and interpersonal communication (pp. 129-156). Newbury Park, CA: Sage. 
Meares, M. M., Oetzel, J. G., Torres, A., Derkacs, D., \& Ginossar, T. (2004). Employee mistreatment and muted voices in the culturally diverse workplace. Journal of Applied Communication Research, 32, 4-27.

Meek, C. B. (2004). The dark side of Japanese management in the 1990s: Karoshi and ijime in the Japanese workplace. Journal of Managerial Psychology, 19, 312-331.

Melkas, T. (2001). Tasa-arvobarometri 2001 [The equality-assessment rating made in 2001] (Tasaarvojulkaisuja No. 9) [Publications on Equality No. 9). Helsinki, Finland: Statistics Finland: Council for Equality (Edita).

Miller, C. T., \& Kaiser, C. R. (2001). Implications of mental models of self and others for the targets of stigmatization. In M. R. Leary (Ed.), Interpersonal rejection (pp. 189-212). New York: Oxford University Press.

Morgan, W. M., \& Wilson, S. R. (2005). Nonphysical child abuse: A review of literature and challenge to communication scholars. In P. Kalbfleisch (Ed.), Communication yearbook 29 (pp. 1-34). Mahwah, NJ: Erlbaum.

Morita, Y., Soeda, H., Soeda, K., \& Taki, M. (1999). Japan. In P. K. Smith, Y. Morita, J. JungerTas, D. Olweus, R. Catalano, \& P. Slee (Eds.), The nature of school bullying: A crossnational perspective (pp. 309-323). London: Routledge.

Mottet, T. P., \& Thweatt, K. S. (1997). The relationship between peer teasing, self-esteem, and affect for school. Communication Research Reports, 14, 241-248.

Naylor, P., \& Cowie, H. (1999). The effectiveness of peer support system in challenging school bullying: The perspectives and experiences of teachers and pupils. Journal of Adolescence, $22,467-479$.

Niedl, K. (1995). Mobbing/bullying am arbeitsplatz [Mobbing/bullying at work]. München, Germany: Rainer Hampp Verlag. 
Niedl, K. (1996). Mobbing and well-being: Economic and personnel development implications. European Journal of Work and Organizational Psychology, 5, 239-249.

O’Connell, P., Pepler, D. \& Craig, W. (1999). Peer involvement in bullying: Insights and challenges for intervention. Journal of Adolescence, 22, 437-452.

Olweus, D. (1973). Hackkycklingar och översittare. Forskning om skolmobbning [Victims and bullies. Research on school bullying]. Stockholm, Sweden: Almqvist \& Wicksell.

Olweus, D. (1978). Aggression in the schools: Bullies and whipping boys. Washington, DC: Hemisphere (Wiley).

Olweus, D. (1993). Bullying at school: What we know and what we can do. Oxford, England: Blackwell.

Olweus, D. (1999). Sweden. In P. K. Smith, Y. Morita, J. Younger-Tas, D. Olweus, R. F. Catalano, \& P. Slee (Eds.), The nature of school bullying: A cross-national perspective (pp. 7-27). New York: Routledge.

Olweus, D. (2003). Bully/victim problems in school: Basic facts and an effective intervention programme. In S. Einarsen, H. Hoel, D. Zapf, \& C. L. Cooper (Eds.), Bullying and emotional abuse in the workplace: International perspectives in research and practice (pp. 62-78). London: Taylor \& Francis.

O’Moore, A. M. (1989). Bullying in Britain and Ireland: An overview. In E. Roland \& E. Münthe (Eds.), Bullying: An international perspective (pp. 3-21). London: David Fulton.

Parker, J. G., \& Asher, S. R. (1993). Friendship and friendship quality in middle childhood: Links with peer group acceptance and feelings of loneliness and social dissatisfaction. Developmental Psychology, 29, 357-389.

Perry, D. G., Kusel, S. J., \& Perry, L. C. (1988). Victims of peer aggression. Developmental Psychology, 24, 807-814. 
Peterson, L., \& Rigby, K. (1999). Countering bullying at an Australian secondary school with students as helpers. Journal of Adolescence, 22, 481-492.

Pikas, A. (1990). Irti kouluväkivallasta [Getting away from violence in schools] ( $2^{\text {nd }}$ ed.). (E. Pilvinen, Trans.). Espoo, Finland: Weilin+Göös.

Poole, M. S. (1999). Group communication theory. In L. R. Frey, D. S. Gouran, \& M. S. Poole (Eds.), The handbook of group communication theory and research (pp. 37-70). Thousand Oaks, CA: Sage.

Poole, M. S., Seibold, D. R., \& McPhee, R. D. (1996). The structuration of group decisions. In R. Y. Hirokawa \& M. S. Poole (Eds.), Communication and group decision making $\left(2^{\text {nd }}\right.$ ed., pp. 114-146). Thousand Oaks, CA: Sage.

Pryor, J. B., \& Fitzgerald, L. F. (2003). Sexual harassment research in the United States. In S. Einarsen, H. Hoel, D. Zapf, \& C. L. Cooper (Eds.), Bullying and emotional abuse in the workplace: International perspectives in research and practise (pp. 79-100). London: Taylor \& Francis.

Rainivaara, S. (2004, November). Communication culture of the workplace and communication behavior as a form of mental violence. Paper presented at the annual meeting of the National Communication Association, Chicago.

Rayner, C. (1997). The incidence of workplace bullying. Journal of Community and Applied Social Psychology, 7, 199-208.

Rayner, C., Sheehan, M., \& Barker, M. (1999). Theoretical approaches to the study of bullying at work. The International Journal of Manpower, 20, 11-15.

Rigby, K. (1997). Attitudes and beliefs about bullying among Australian school children. Irish Journal of Psychology, 18, 202-220. 
Rigby, K. (1998). The relationship between reported health and involvement in bully/victim problems at school among male and female secondary schoolchildren. Journal of Health Psychology, 3, 465-476.

Rigby, K., \& Slee, P. T. (1991). Bullying among Australian school children: Reported behavior and attitudes toward victims. Journal of Social Psychology, 131, 615-627.

Roland, E. (2002a). Aggression, depression and bullying others. Aggressive Behavior, 28, 198-206.

Roland, E. (2002b). Bullying, depressive symptoms and suicidal thoughts. Educational Research, $44,55-67$.

Roland, E., Bjørnsen, G., \& Mandt, G. (2003). Taking back adult control: A report from Norway. In P. K. Smith (Ed.), Violence in schools. The response in Europe (pp. 200-215). London: Routledge.

Roland, E., \& Galloway, D. (2002). Classroom influences in bullying. Educational Research, 44, 299-312.

Ross, D. M. (1996). Childhood bullying and teasing: What school personnel, other professionals, and parents can do. Alexandria, VA: American Counseling Association.

Ryynänen, S. (2003). Sukupuolinen häirintä vuorovaikutustilanteena [Sexual harassment as a communication situation]. Unpublished master's thesis, University of Jyväskylä, Jyväskylä, Finland.

Salin, D. (2001). Prevalence and forms of bullying among business professionals: A comparison of two different strategies for measuring bullying. European Journal of Work and Organizational Psychology, 10, 425-441.

Salmivalli, C. (1998). Koulukiusaaminen ryhmäilmiönä [Bullying as a group process]. Tampere, Finland: Gaudeamus.

Salmivalli, C. (2002). Suhdeskeemat, sosiaaliset tavoitteet ja sosiaalinen käyttäytyminen [Relational schemas, social goals, and social behavior]. Psykologia, 37, 84-92. 
Salmivalli, C. (2003). Koulukiusaamiseen puuttuminen: kohti tehokkaita toimintamalleja [Interventions in bullying: towards effective practices]. Jyväskylä, Finland: PS-kustannus.

Salmivalli, C., Karhunen, J., \& Lagerspetz, K. (1996). How do the victims respond to bullying? Aggressive Behavior, 22, 99-109.

Salmivalli, C., \& Kaukiainen, A. (2004). "Female aggression" revisited: Variable- and personcentered approaches to studying gender differences in different types of aggression. Aggressive Behavior, 30, 158-163.

Salmivalli, C., Kaukiainen, A., \& Lagerspetz, K. (2000). Aggression and sociometric status among peers: Do gender and type of aggression matter? Scandinavian Journal of Psychology, 41, $17-24$.

Salmivalli, C., Lagerspetz, K., Björkqvist, K., Österman, K., \& Kaukiainen, A. (1996). Bullying as a group process: Participant roles and their relations to social status within the group. Aggressive Behavior, 22, 1-15.

Salmivalli, C., \& Voeten, M. (2004). Connections between attitudes, group norms, and behaviors associated with bullying in schools. International Journal of Behavioral Development, 28, 246-258.

Sharp, S., \& Smith, P. K. (1991). Bullying in UK schools. The DES Sheffield bullying project. Early Child Development and Care, 77, 44-55.

Slee, P. T. (1994). Situational and interpersonal correlates of anxiety associated with peer victimization. Child Psychiatry and Human Development, 25, 97-107.

Smith, P. K., \& Madsen, K. (1999). What causes the age decline in reports of being bullied at school? Educational Research, 41, 267-286.

Smith, P. K., Morita, Y., Junger-Tas, J., Olweus, D., Catalano, R., \& Slee, P. (Eds.). (1999). The nature of school bullying: A cross-national perspective. London: Routledge. 
Smith, P. K., \& Sharp, S. (Eds.). (1994). School bullying: Insights and perspectives. London: Routledge.

Smith, P. K., Talamelli, L., Cowie, H., Naylor, P., \& Chauhan, P. (2004). Profiles of non-victims, escaped victims, continuing victims and new victims of school bullying. British Journal of Educational Psychology, 74, 565-581.

Smorti, A., Menesini, E., \& Smith, P. K. (2003). Parents' definitions of children's bullying in a five-country comparison. Journal of Cross-Cultural Psychology, 34, 417-432.

Spitzberg, B. H., (1994). The dark side of (in)competence. In W. R. Cupach \& B. H. Spitzberg (Eds.), The dark side of interpersonal communication (pp. 25-50). Hillsdale, NJ: Lawrence Erlbaum.

Spratlen, L. P. (1995). Interpersonal conflict which includes mistreatment in a university workplace. Violence and Victims, 10, 285-297.

Tasala, M. (1997). Työpaikkakiusaamisen noidankehät [The vicious circles of workplace bullying]. Jyväskylä, Finland: Gummerus.

Taylor, D., \& Altman, I. (1987). Communication in interpersonal relationships: Social penetration processes. In M. Roloff \& G. Miller (Eds.), Interpersonal processes: New directions in communication research (pp. 257-277). Newbury Park, CA: Sage.

Taylor, J. R., Flanagan, A. J., Cheney, G., \& Seibold, D. R. (2001). Organizational communication research: Key moments, central concerns \& future challenges. In W. B. Gudykunst (Ed.), Communication yearbook 24 (pp. 99-138). Thousand Oaks, CA: Sage.

Teräsahjo, T., \& Salmivalli, C. (2002). "Se tavallaan haluu olla yksin”. Koulukiusaamisen tulkintarepertuaarit ala-asteen oppilaiden puheissa ["In a way he wants to be alone". The repertoires of interpretation concerning school bullying in the talk of primary-school pupils]. Psykologia, 37, 101-114. 
Thylefors, I. (1987). Syndabockar. Om utstötning och mobbning i arbetslivet [Scapegoats. On expulsion and bullying in working life]. Stockholm, Sweden: Natur och Kultur.

Timmerman, G., \& Bajema, C. (1999). Sexual harassment in European workplaces. In Sexual harassment at the workplace in the European Union (pp. 1-154). Luxembourg, Luxembourg: Office for Official Publications of the European Communities.

Underwood, M., Galen, B., \& Paquette, J. (2001). Top ten challenges for understanding gender and aggression in children: Why can't we all just get along? Social Development, 10, 248-266.

Underwood, M. K., Scott, B. L., Galperin, M. B., Bjornstad, G. J., \& Sexton, A. M. (2004). An observational study of social exclusion under varied conditions: Gender and developmental differences. Child Development, 75, 1538-1555.

Vartia, M. (1991). Bullying at workplaces. In S. Lehtinen, J. Rantanen, P. Juuti, A. Koskela, K. Lindström, P. Rehnström, \& J. Saari (Eds.), Towards the 21st century. Proceedings from the international symposium on future trends in the changing working life (pp. 131-135).

Helsinki, Finland: Institute of Occupational Health.

Vartia, M. (1993). Psychological harassment (bullying, mobbing) at work. In K. KauppinenToropainen (Ed.), OECD panel group on women, work, and health (pp. 149-152). Helsinki, Finland: Ministry of Social Affairs and Health.

Vartia, M. (1996). The sources of bullying - Psychological work environment and organizational climate. European Journal of Work and Organizational Psychology, 5, 203-214.

Vartia, M., \& Perkka-Jortikka, J. (1994). Henkinen väkivalta työpaikoilla. Työyhteisön hyvinvointi ja sen uhat [Mental violence in workplaces. The well-being of the working community and the threats facing it]. Tampere, Finland: Gaudeamus.

Vartia-Väänänen, M. (2003). Workplace bullying: A study on the work environment, well-being and health (People and work, Research reports No. 56). Helsinki, Finland: Finnish Institute of Occupational Health. 
Veale, C., \& Gold, J. (1998). Smashing into the glass ceiling of women managers. Journal of Management, 17, 17-26.

Vikat, A. (1998). Kiusaamisen yleisyys ja riskitekijät [The prevalence and risk-factors of bullying] (Abstract). Kouluterveys 2002, 6, 30-32.

Weir, E. (2001). The health impact of bullying. Canadian Medical Association Journal, 165, 12491252.

Whitney, I., \& Smith, P. K. (1993). A survey of the nature and extent of bullying in junior/middle and secondary schools. Educational Research, 35, 3-25.

Wilson, C. B. (1991, July). U.S. businesses suffer from workplace trauma. Personnel Journal, 70, 47-50.

Wilson, S. R., \& Sabee, C. M. (2003). Explicating communicative competence as a theoretical term. In J. O. Greene \& B. R. Burleson (Eds.), Handbook of communication and social interaction skills (pp. 3-50). Mahwah, NJ: Lawrence Erlbaum.

Zapf, D. (1999). Organisational, work group related and personal causes of mobbing/bullying at work. International Journal of Manpower, 20, 70-85.

Zapf, D., \& Einarsen, S. (2001). Bullying in the workplace: Recent trends in research and practice an introduction. European Journal of Work and Organizational Psychology, 10, 369-373.

Zapf, D., \& Gross. C. (2001). Conflict escalation and coping with workplace bullying: A replication and extension. European Journal of Work and Organizational Psychology, 10, 497-522.

Zapf, D., Knorz, C., \& Kulla, M. (1996). On the relationships between mobbing factors, and job content, social work environment and health outcomes. European Journal of Work and Organizational Psychology, 5, 215-238. 